\title{
OrganizationScience
}

Articles in Advance, pp. 1-26

ISSN 1047-7039 (print) . ISSN 1526-5455 (online)

\section{The Replication Dilemma Unravelled: How Organizations Enact Multiple Goals in Routines Transfer}

\author{
Luciana D’Adderio \\ Strathclyde Business School, University of Strathclyde, 199 Cathedral Street, Glasgow G4 0QU, United Kingdom \\ luciana.d-adderio@strath.ac.uk
}

Keywords: routines; change; innovation; replication; goals; artifacts; communities

I examine how organizations address the replication dilemma by simultaneously enacting contrasting goals while transferring routines across complex organizational settings. I address this issue by drawing on a qualitative case-based inquiry into the multiplicity of the routines ostensive and performative aspects in the context of routines transfer and exact replication. The subject of inquiry is a leading electronics organization facing the dilemma of how to deal with simultaneous competing pressures to copy exactly (replicate) and change (innovate). I find that organizational members address this dilemma, first, by harnessing artifacts and communities to establish two sets of ostensive patterns and performances, one supporting alignment (replication) and one improvement (innovation); and, second, by striving to maintain a dynamic balance between them by enacting them in different proportions. This allows offsetting competing goals and the related pressures both at specific points in time, and over time. Building on these findings, I develop a theoretical framework which adds to the extant replication and routines literatures, and the Carnegie account of routines transfer and goal balancing, by capturing: (1) the micro-level, performative dynamics by which organizations unravel the replication dilemma in routines transfer while addressing competing goals and the associated pressures, and (2) the role of the social and material features of context in the (re)production and transfer of routines.

Keywords: routines; change; innovation; replication; goals; artifacts; communities

\section{Introduction}

The exact transfer or replication of a firm's successful routines - or 'best practices' - is a key driver of firm growth and profitability (Winter and Szulanski 2001). Often referred to as the 'McDonald's approach', replication involves creating and operating a number of similar facilities that deliver the same product or service at different geographic locations (ibid). A strategic means to leverage a firm's knowledge assets, the replication of a successful template (working example, or superior operational routine) provides a fundamental source of competitive advantage (Winter 1995, Teece et al. 1997, 
Argote and Ingram 2000, Winter and Szulanski 2001, Jensen and Szulanski 2007, Rivkin 2001, Szulanski and Jensen 2008) for organizations operating in a variety of sectors including retailing, fast food, banking, hotels and consulting services (Winter and Szulanski 2001, Winter et al. 2012).

Despite its strategic value, however, replicating routines, and the related 'web of coordinating relationships' (Winter 1995) across multiple locations is far from trivial. It involves "the creation of another routine that is similar to the original routine in significant respects" (Szulanski and Jensen 2004: 349). Similarity, in this context, entails recreating an abstract pattern - which is recognized as 'the same routine' - at a different organizational location where "a different but similar set of resources is coordinated by a very similar web of relationships" (Winter 1995: 149-150). But just how similar should the pattern be in order to preserve the value of the original template while reaping the learning and adaptation opportunities available and responding to the threats that arise as a consequence of exposure to a new location? In this respect, authors (Winter and Szulanski 2001, Winter et al 2012) have highlighted a crucial tension between the need for reproducing the template exactly (replication) and the need for changing the template (innovation). While, on one hand, complexity and causal ambiguity demand precise replication of the template for guidance and diagnostic purposes, on the other, deferring changes can significantly reduce the effectiveness of the transfer, by preventing the introduction of improvements and innovations, and delaying adaptation to the local context.

Winter and Szulanski (2001) have referred to the tension between replication (copying the template exactly) and innovation (changing or adapting the template) as the 'replication dilemma' (737). Similar to the exploration-exploitation quandary (March 1991), the dilemma captures the trade-off between the advantages of precision and those of learning and adaptation (ibid). Scholarly analysis of the tension between innovation and replication, however, has been so far limited in scope (Winter et al. 2012). Existing studies have mostly focused on simple organizations (i.e. food franchises) where the incentives to innovate (change, improve, adapt, Szulanski and Jensen 2008) may not be so high, due to the relative simplicity of the recipe, the replicator organization and the recipient environment. This raises the question of how the dilemma might unfold in the case of more complex organizations where the conflicting goals of innovation and replication compete relentlessly for scarce resources.

In more complex cases, how do organizations learn to address the replication dilemma and respond to the coexisting and contrasting pressures for innovation and replication? Answering this question will allow us to theorize how routines are reproduced across more complex and distributed settings, and, more in general, how organizations are able to address multiple conflicting and coexisting goals which simultaneously pull towards exploration and exploitation. To this purpose, I posit, we need to pay closer attention to the micro-level, context-related mechanisms created and invoked by organizations in their attempt to replicate routines and balance multiple goals and the associated 
pressures in the case of more complex transfers. This, in turn, calls for an investigation into the role of context in routines transfer, including the role of social (groups, teams and communities) and material (objects, technologies, artifacts) features of context in enacting patterns which mediate the tension between exact reproduction and adaptation.

Organizational communities (Lave and Wenger 1991) typically enact different - and constantly shifting - knowledge and understandings which influence the extent to which a template is adopted and the precision with which it is reproduced. Material artifacts, including everyday objects and more complex technologies (Bechky 2003, Carlile 2004), may be designed by communities to reflect and support their knowledge and assumptions, therefore also contributing to shaping routines in far more fundamental ways than scholars have acknowledged to date. Due to their multiple, emergent and dynamic properties, communities and artefacts not only help transfer knowledge and routines but contribute to their continuous evolution and transformation (ibid). The closer investigation of the social and material context in its complexity would also appear to suggest that context itself, the actors' knowledge and preferences and the tools that they use to support their goals, may change as a consequence of being involved in routines, again with important implications for routines reproduction. All of this suggests a much more complex relationship between routines and the context in which they are embedded (Granovetter 1985) than has been allowed so far both in the routines literature (Cohen et al. 1996) and the Carnegie account of routine replication (Winter and Szulanski 2001) and goal balancing (March 1991, Cyert and March 1992, Levinthal and March 1993).

In this study, I therefore set out to theorize the dynamic, micro-level processes by which organizations address the replication dilemma by striving to offset the contrasting pressures for innovation and replication both in the short-term and over time. I do so by drawing on the three-year ethnography of the transfer of routines underpinning the production capability for a computer server at a leading electronics organization. Here I have focused on how routines change over time as they are transferred across organizational locations. In my quest to unravel routines dynamics I adopt a definition of routine as "a repetitive, recognizable pattern of interdependent actions, carried out by multiple actors" (Feldman and Pentland, 2003: 95). As dynamic, generative systems routines are constituted through the interaction of 'performative' and 'ostensive' aspects (Feldman and Pentland 2003). To capture the multiple perspectives of participants on routines change and the variety of their performances (Pentland and Feldman 2005, Howard-Grenville 2005), I have conducted a wide range of observations and interviews across different parts of the organization, at different levels of the organizational hierarchy and along different transfer stages. This constitutes a first attempt to conduct a fine-grained, longitudinal study of routines transfer and replication. 
The findings advance replication and routines theory, as well as adding to our understanding of how organizations learn to deal with multiple, contrasting goals. I find that organizational members respond to simultaneous pressures for replication and innovation by creating and maintaining two sets of ostensive patterns and performances, one supporting alignment to the template (replication) and one improvement (innovation). They do so by enacting routines selectively through a range of social and material features which favour one goal while relegating the other to the background. Over time, I find that organizations are able to support each goal (innovation or replication) alternatively by performing and therefore energizing the set of patterns (alignment or improvement) which supports that goal. These micro-level, sociomaterial mechanisms assist organizations in their continuously challenged and necessarily incomplete effort to achieve a dynamic balance between competing but coexisting goals, both in the short and the longer term. Building on these findings, I develop a theoretical model of the process by which routines participants attempt to dynamically enact contrasting pressures for innovation and replication.

\section{The replication dilemma: addressing competing goals in routines transfer}

Organizational scholars studying replication (Winter and Szulanski 2001) have identified a crucial trade-off between the need for reproducing a template precisely and the need for changing or adapting the template. On one hand, attempting to modify a complex and imperfectly understood formula can be deleterious to performance (Winter et al 2012). When a template is complex and causally ambiguous, any modifications can prevent meaningful comparisons between the replica and the original template. Changes, for example, tend to complicate cause-effect relationships (Szulanski and Jensen 2006). They can produce unforeseen negative interactions the causes of which are difficult to trace back and eradicate, thus reducing the performance of the replica, as well as preventing the original working example from functioning as a referent for the purpose of guidance and diagnosis (Winter et al. 2012). In the presence of complexity and ambiguity there are therefore strong rationales for copying the template precisely and preventing any deviations from the successful formula. On the other hand, there can be equally strong rationales in favour of modifying the template. Copying the template too closely can in fact decrease transfer effectiveness by preventing innovations and adaptation to the local environment (Bartlett and Ghoshal 1989) while also generating local resistance to adoption (Szulanski and Jensen 2008).

While the extant work has typically focused on relatively simple transfers across organizations ranging from retail franchises (Love 1995, Darr et.al 1995, Argote and Darr 2000) to banking (Winter and Szulanski 2001), we can expect the tensions between innovation and replication to emerge even more acutely in more complex and distributed settings. On one hand, the greater product and technological complexity that characterizes such contexts implies stronger causal ambiguity which in turn for copying exactly (preserving the value of the template by freezing). On the other, in more 
complex and distributed organizations we can expect the pressures for modifying and adapting the template to soar exponentially during the course of transfer and beyond. Factors such as local knowledge bases and the recipient's expertise and experience can weigh heavily against aligning to the original template and in favour of change. In high-technology and rapid innovation contexts, moreover, we can expect strong pressures for introducing changes in the form of radical innovations and/or incremental improvement, both of which are typically either denied or significantly delayed under a regime that freezes the template for a period of time (months or even years, in the case of a complex transfer). In more complex organizational settings we can expect several of these factors to emerge simultaneously and challenge the decision to freeze the template at every stage of the transfer process and beyond. This raises the important question of how the contrasting goals of innovation and replication, and the competing pressures that ensue, can be addressed in the short and long term.

The issue of how organizations are able to address both innovation and replication is closely related, in more abstract terms, to how organizations manage multiple, contrasting goals across organizational locales and over time. The fact that organizational members hold widely divergent views, goals and interests is well documented in the organizational literature. Behavioral theories of decision making (Cyert and March 1992), for example, address directly the issue of heterogeneous preferences and how organizations may be able to approach them. The issue, moreover, spans beyond the individual level. Heterogeneous preferences and information sets by individual actors typically become aggregated into multiple organizational level goals that are often weakly correlated (Ethiraj and Levinthal 2009) and therefore can lead to conflict. In theory, this poses significant challenges for boundedly rational actors who are typically unable to integrate across contrasting goals, potentially leading to a freezing in behaviour towards the status quo (Simon 1955).

In practice, however, organizations are able to devise mechanisms that help them deal with multiple conflicting goals (Meyer 2002, Ethiraj and Levinthal 2009). Management strategies aimed at providing actors with an incomplete view of the full organizational set of goals, can, for instance, provide decision-makers with the necessary focus and clarity required to overcome the freeze (Ethiraj and Levinthal ibid). This is the case of 'sequential attention' (ibid), a strategy based on the selective shifting of attention between goals over time, which helps defer conflict by encouraging firms to focus on one goal at a time. This important mechanism, however, rests on the assumption that actors "rarely see conflicting objectives simultaneously" (Cyert and March 1992:41) and therefore "the probability is low that [competing] demands are made simultaneously" (ibid), a supposition which does not always materialize. Organizations are becoming increasingly more complex and distributed, and their environments increasingly unstable and fast-changing. Under these conditions, the probability is not so low that competing demands are made concurrently, causing conflict to remain present and visible despite attempts to defer it by focusing on one goal at a time. This begs the question of how organizations may be able to manage multiple contrasting goals and the related 
pressures which are experienced simultaneously and cannot be easily - or completely - deferred. This is precisely the case of more complex organizations facing the replication dilemma.

The organization examined in this paper offers vantage points to address this topic, as it is facing multiple goals (copying the template exactly, or replicating, vs. changing the template, or innovating) which coexist and appear to be mutually exclusive, at least in the short term (Winter 2010). The way transfer participants are able to address the tensions generated by the clash between innovation and replication and the ensuing conflict, is bound to have fundamental consequences for routines transfer. Organizational scholars in the Carnegie tradition have made substantial progress towards unravelling this important phenomenon. The complexity of the issue, however, demands a finer-grained and more dynamic approach which centres on practices and allows for the simultaneous coexistence of contrasting goals, thus addressing an important gap in the organizational literature.

Even when authors have focused on the role of practices in simultaneously balancing exploration and exploitation (ambidexterity), they have in fact mostly ascribed to a dualistic view (cf. Farjoun, 2010) which sees exploration and exploitation as entailing different, almost diametrically opposed, routines, mind frames and processes (March 1996, Benner and Tushman 2003). In contrast, more recent contributions (Raisch et al. 2009) have suggested that organizations may be able to pursue the two activities by reconfiguring their processes dynamically and have called for studies that "address questions on the dynamic processes underlying organizational ambidexterity" (693). Capturing how organizations attempt to simultaneously deal with the contrasting pressures for exploration and exploitation while addressing the replication dilemma, I posit, entails focusing on the micro-level, dynamic and sociomaterial processes by which tensions are managed. This is where routines theory becomes especially useful.

The multiplicity of individual interpretations (Feldman and Pentland 2003, Pentland and Feldman 2005) and orientations (Howard-Grenville 2005) and their relationship to organizational goals have attracted substantial interest from routines scholars. Nelson and Winter's (1982) metaphor of routines 'as truces', for example, explains how divergent interests and objectives held by various actors (Simon 1947, Cyert and March 1992) could be temporarily coordinated through the use of authority and hierarchy. While usefully capturing the political side of routines, however, earlier approaches have focused more on the outcome (stability achieved through the reduction of conflict), than the actual processes by which divergent individual goals and interests can be coordinated (Feldman and Pentland, 2003; Zbaracki and Bergen, 2010). More recent evidence points to the fact that stability and instability, truces and conflict may not be mutually exclusive but rather coexist in routines (ibid).

Routines theory has begun to address this issue by focusing on the routine's internal dynamics and the multiplicity of the ostensive and performative aspects (Feldman 2000). Feldman and Pentland have opened up this discussion by highlighting how routines are produced by "many people with different 
information, preferences, and interpretation" (2003: 115). The ostensive aspect of the routine, for example, is not a single, unified object, but is distributed unevenly (ibid:101). In addition, the fact that routines "are enacted over time and space" (ibid:115) increases the possibility for different perceptions and interpretations. Feldman (2003), for example, shows how the routine can be interpreted differently by actors in various roles. University accommodation supervisors, for example, can hold very different ostensive views of the routine and this bears fundamental consequences for organizational stability and instability. Howard-Grenville (2005) has studied how divergent understandings by various actors impinge on performance variability, while showing how multiple intentions and orientations may become integrated into a collective coordinated performance. Similarly, Zbaracki and Bergen (2010) show how sales and marketing groups can have different representations of the problem at hand which persist, at times leading to overt conflict which induces breaks in the prevailing truce. In this case hierarchy is drawn upon to subsume divergent interpretations under the greater common goal of making the price-adjustment process work, despite the underlying differences. Focusing on waste collection routines, Turner and Rindova (2012) show how organizations balance contrasting pressures for consistency and change by creating and enacting multiple (but ultimately complementary) ostensive patterns, through harnessing artifacts and connections (ibid). Artifacts and communities are identified as key contextual features enacting multiple and divergent ostensive views and performances (D'Adderio, 2008 and 2011), thus (re)configuring routines in fundamental ways.

The routines literature has provided some important insights into the multiplicity of the routines' ostensive and performative aspects. So far, however, authors have mostly focused on relatively simpler tasks and organizations, where coordination is less of a hurdle due to a low(er) extent of complexity and/or diversity. In more complex and distributed cases, such as the one studied here which combines high task complexity and ambiguity with high organizational heterogeneity, it is even less likely that multiple, contrasting views may be consolidated into a single high-level ostensive pattern (Feldman and Pentland 2003); nor is it probable that they may be readily mapped onto common, shared and overarching organizational goals. Similarly, multiple, conflicting but coexisting performances may not be easily harmonized over time and across organizational locations which are characterized by equally strong and competing 'characters' (Birnholtz et al. 2007).

The exact replication of the complex bundle of routines which underpin a distributed high-technology manufacturing capability, can therefore provide new insights into the mechanisms that help coordinate diverse and distributed performances into coherent ecologies of action patterns (Birnholtz et al. 2007, Turner and Rindova 2012) both across organizational locations and over time. While recent contributions have suggested that the social and material features of context might play a role (ibid), it is as yet unclear precisely how actors and artifacts, and their heterogeneous configurations (Suchman 2007, D'Adderio 2008 and 2011), might contribute towards shaping routines while dynamically 
orienting views and actions towards fulfilling multiple organizational goals. It is possible, for example, that sociomaterial ensembles may generate both complementary and competitive withinand between-routines dynamics which in turn may affect the organization's ability to address multiple goals and the associated tensions.

The study of the exact transfer of routines across heterogeneous domains therefore provides vantage points to further these theoretical inquiries. Here the presence of conflicting organizational goals (innovation and replication) reinforces and reflects a divergence in both understandings (i.e. about the purpose or target of the routine) and performances (i.e. the actual specific action sequence which enacts a certain routine) both within routines and across routines. The way in which multiplicity is coordinated has important bearing over the organization's ability to engage multiple objectives. How are routines replicated in the presence of multiple, contrasting goals? In particular, how are routines participants able to manage simultaneous competing pressures for copying exactly (replication) and change (innovation), both in the short term and over time?

\section{Methods}

\section{Research setting}

To determine how organizations unravel the replication dilemma I draw from the valuable case of the transfer of routines at a leading manufacturing organization. This is a Fortune 500 top-ranked, USbased electronics manufacturer with a 35,000 global workforce and annual turnover of $\$ 10 \mathrm{bn}$ (at the time of fieldwork). The organization has embarked on the $\$ 30 \mathrm{~m}$ transfer of a complex server product and related manufacturing capability, from one of their US production sites to a newly acquired site in the UK. This setting provides several vantage points to unravel the replication dilemma. First, the subject of enquiry is a complex and distributed organization operating in a high technology, rapid innovation domain. This demanding context exposes the organization to significant, simultaneous and contrasting pressures for innovation and replication. It can therefore provide new insights into how organizations replicate routines while attempting to balance contrasting goals. Second, this rich and extended case study provides at the same time both an in-depth and a longitudinal overview of the exact transfer of routines. This affords a dynamic perspective on how routines change in the short term and over time as they are transferred across heterogeneous settings. Third, the situated (Suchman 1987) micro-level analysis adopted here provides fertile terrain to capture change not only within but also across a number of routines, thus potentially shedding new light over their ecological dimension (Birnholtz et al. 2007, Turner and Rindova 2012). The in-depth, extended study of routines transfer in a complex, distributed and rapidly shifting context where there are strong, simultaneous and competing pressures for replication and innovation provides a valuable setting to study how organizations unravel the replication dilemma and the role of routines in enacting multiple goals. 


\section{Data collection: an ethnography of 'copy exactly'}

\section{Participant observation}

I was a resident researcher at the manufacturer's destination facility for the duration of transfer, from ex-ante planning to post-transfer testing. As a full-time academic I was able to exercise complete independence in conducting my enquiry throughout this period. My visits were most frequent during the central transfer stage. During this two-year period I visited almost daily, my visits spanning between 2.5-5 hours and the entire day. The intern status I enjoyed allowed privileged access to the micro-dynamics of routines transfer. Direct observation brought many benefits including reducing the need to rely solely upon the respondents' perception of transfer accuracy, which can significantly differ from actual data. I collected data by attending weekly Project, Engineering, Materials, Product, Process and Software meetings, as well as by monitoring shop floor operations (about 120 meetings in total, plus regular visits to the shop floor). I gathered key additional evidence through participating regularly in telephone- and video-conferences with the US team (one tele-conference/week for each functional group, plus periodic inter-functional and inter-site video conferences). I also attended quarterly inter-site face-to-face meetings, each typically lasting three days. I used journals to take field notes throughout, except when it felt intrusive or out of place as on informal occasions. As a member of the transfer team I had the opportunity to talk informally to practitioners on site, as well as being invited along to social outings where the US and UK teams shared experiences and anecdotes.

\section{Interviews}

I conducted a total of 36 in-depth, semi-structured interviews. The sample of informants was carefully chosen to cover - and be similarly spread across - most organizational functions (i.e. Project Management, Product Engineering, Test Engineering, Analysis, Training, Production, Manufacturing) and levels (Directors, Product, Process and Project Managers, Engineering, Manufacturing and Test Managers, IT Managers, Failure Analysts, Test and Shop Floor Technicians). While individual interviewees were selected by giving priority to those directly involved with the transfer project, interviews were also extended as much as possible to include practitioners beyond the transfer teams (i.e. inventory controllers, supplier reps, software engineers). I also held an additional series of indepth, semi-structured and unstructured interviews with the US team whilst in the UK (about six interviews per quarter to managers, engineers and technicians). An example of the interview protocol can be found in Table 1. I used the interviews, which were fully recorded and transcribed, to follow up leads that emerged from observations, meetings or email exchanges; to verify data collected during observations; to gather different opinions over key issues; and to collect background information.

\section{Artifacts and additional resources}

I was fortunate to be entrusted with a corporate (microchip-embedded) ID card. The card warranted unrestricted access to premises, a corporate email account, membership of internal email aliases and 
access to the corporate intranet. I also obtained additional evidence through more traditional kinds of artifacts including documents, diagrams, flowcharts, sketches and Powerpoint presentations.

\section{Data analysis}

The analysis overlapped partially with the observation period, and intensified substantially towards the end of the project. Upon project completion, marked by the start of production at destination, I began to reduce my visits to gain detachment from the field and allow for the writing up stage to begin in earnest. I began by analysing the data and compiling it into an in-depth case study consistent with an inductive (Eisenhardt 1989; Miles and Huberman 1994), 'grounded theorizing' approach (Glaser and Strauss 1967). This involved proceeding in an iterative manner, scanning the data for recurrent concepts and themes and consolidating these inductively into emergent categories (Orlikowski 2002). Analysis of the data revealed some key dynamics as yet unreported in the literature. A key dynamic to emerge was the simultaneous presence of contrasting organizational goals, innovation and replication, and the associated competing pressures for alignment or improvement. These pressures were enacted differently by different organizational communities and artifacts, and their relative emphasis appeared to shift significantly over time.

The presence of multiple goals and contrasting pressures emerged strongly from the data from the early phases and persisted throughout the transfer. I was thus led early on to focus on the contrasting views and actions that appeared to support either copy exactly/replication (pressure to align) or change/innovation (pressure to improve). A key early finding was the clustering of emergent categories around two distinct stages, transfer and post-transfer. Stages captured "empirically observed temporal pattern(s)" (Langley and Tsoukas 2010) which showed (partial) convergence around replication for a period of time, and then around innovation. In the transfer stage, prevailing first-order concepts (Van Maanen 1979) included alignment, copy exactly, sameness, mirror image, carbon copy, drag and drop, cut and paste. I coded these as pressures to align. In the post-transfer stage, prevailing notions included dis-alignment, improvement, drift, innovation, gaps, leapfrogging. I coded these under pressures to improve. The other interesting trend offered by the data was how the relative emphasis on each type of pressure changed over time. The data clustering clearly reflected the transition from a stage characterized by a strong mandate to copy exactly (alignment), where innovation was relegated to the background, to a stage where innovation (improvement) gained emphasis, this time relegating copy exactly to the background. The analysis thus pointed to a significant shift in the extent to which individual goals were supported over time, and a realignment of ostensive patterns and performances to produce and reflect this shift.

The second key dynamic to emerge from the data was the high extent of diversity amongst views and actions across organizational locations and levels. Functions, teams, or communities for example, could be oriented towards alignment (i.e. the FINAO community) or improvement (i.e. the 
engineering community) and this changed over time. I coded references to organizational collectives including 'groups', 'teams', 'functions' or 'cultures' in relation to alignment or improvement under communities. Organizational communities appeared from the outset to be involved in the creation and use of a complex array of artifacts (models, rules, procedures, lists, etc.) which helped them orient their views and efforts towards alignment or improvement. I coded this latter category as artifacts. Similarly to communities, the type and characteristics of the artifacts invoked changed over time during the course of transfer.

Subsequently, I proceeded to evolve emerging categories through comparison with existing theoretical categories in organizational and routines theory (Nag et al. 2007). This creative, but firmly grounded process (Suddaby 2006) led to developing new concepts, which were later compared against field data for further validation. I coded the shift towards replication or innovation as orienting (Okhuysen and Bechky, 2009), and specifically focused on the role of artifacts and communities in supporting alignment or improvement through standardizing or orchestrating (reducing or increasing variation from the template). Through this process I was able to develop a new framework which captures how (and how far) multiple, contrasting goals were enacted both in the short term and over time, how routines participants attempted to balance the resulting tensions, and the sociomaterial (Orlikowski and Scott 2008) mechanisms through which goals and tensions were addressed.

\section{Findings: performing innovation and replication in routines transfer}

In this paper I explore how organizations unravel the replication dilemma in routines transfer by addressing the tensions resulting from the coexistence of multiple, contrasting goals. I do so by illustrating how routines participants attempt to balance pressures to copy exactly (replicate) or change (innovate) during the course of a complex routines transfer by creating and invoking a dedicated range of artifacts and communities which help orienting routines towards alignment or improvement. In my quest, I draw from the story of the exact replication of an outstanding machine, which, at the time of fieldwork, was the world's largest and most expensive computer server. Highend servers are sophisticated hardware technologies used by companies to run a number of services including managing corporate databases, email and internet access. The brainchild of a highly reputable, pioneering US-based division of the corporation, this machine was enjoying at the time a strong surge in market demand. The transfer project was initiated with the aim of increasing the manufacturer's production capacity to meet the forecasted escalating global demand for high-end computers. The decision to replicate this hugely successful recipe was seen from the outset as the obvious strategy as it would allow to rapidly double production capacity, while at the same time providing better access to critical geographical markets in the Europe and Middle East Asia region. 
The move entailed the full articulation, codification, transfer and validation of the entire production meta routine, and all related subroutines (i.e. assembly, testing, shipping, etc.) for this outstanding computer from their US-based facility to a recently acquired site in the UK. Intel's 'Copy Exact!' approach (McDonald 1998, Winter and Szulanski 2001, Iansiti and West 2003) was the strategy selected early on to guide this transfer, due to its intrinsic complexity and in recognition of the contrasting requirements to which these sophisticated machines are typically exposed. On one hand, the criticality of the activities and data managed by the server at customer sites called for the highest quality and reliability in the field. On the other, the delivery of high performance, flexibility and customization created strong demands for innovation and improvement, which are essential to retain a competitive edge in this fast-moving market segment. The contrasting but concurrent requirements for high quality and reliability, on one hand, and innovation and improvement, on the other, generated from the outset strong conflicting pressures for copy exactly/replication and change/innovation which unravelled throughout the transfer and beyond. In the sections that follow, I retrace the history of this remarkable transfer project, focusing on how the contrasting pressures highlighted above played out in the short term and over time, and the role of routines and their context in helping to deal with these pressures.

\section{Transfer}

Transfer involved the monumental task of 'uplifting' routines from origin and their painstaking reconstruction at destination, "[...] basically, a massive and very complex transition” (US project manager).This task involved capturing routines as they were performed at origin through direct observation as well as reference to written manuals. Once captured, routines were codified and written down as a set of detailed step-by-step production sequences which were subsequently coded into a common Computer Model made available to both sites. Engineers at destination used the observations and the computer model as a basis to recreate routines at their site.

\section{Pressure for alignment}

At the beginning of transfer, the pressure to replicate prevailed over the pressure to innovate (change, adapt, improve) (Table 2). The widespread belief at that point was that maintaining strict alignment between origin and destination was the only means to succeed under such complex transfer conditions. As explained by a US manager,

The $[\ldots]$ imperative we had early on in the product was that it had to be 'mirror image'. So we coined that phrase, the idea was hold the mirror up to the process in [origin] and it's really what you want to build. You want it to look the same, you want the people to look the same, their training, their attitude, the way they approach the job, the actual job they do: everything has to be the same (US manager)

And also, 
The core belief is that the products have to be 'mirror image' (UK manager)

There were several reasons behind their faith in this exacting rationale. First, complexity and instability are so high for this kind of product that deviating from the template could rapidly escalate, leading to loss of product quality and reliability. As explained by a US manager,

[...] If [destination] went off and created their own version of the manufacturing process, and knowing how unstable the product was and how complex the process of building and testing it is, we knew that they would fail $[\ldots]$ and then both groups [origin and destination] would suffer as a result.

In the presence of high product and technological complexity, in fact, any changes from the 'golden formula' are likely to generate unforeseen interactions (Winter et al 2012). These might cause computers to fail catastrophically in the field, causing long-term damage to a producer's reputation, as in the case of outages at large, mission-critical customer organizations such as banks and hospitals.

The sense we had was a ripple, when you throw a rock into a pond, and the ripples cascade outwards, a relatively small difference can have far reaching effects. And so what we wanted to do was minimise the exceptions, the small changes $[\ldots]$ because we feared that just a couple of changes could have so many far reaching effects that ultimately the products do not even cost the same. (US manager)

Another related reason to copy exactly was that it enabled solving any emerging product and process issues arising during the course of the transfer by allowing meaningful comparisons with the original template, which would henceforth act as a referent for diagnosis.

$[\ldots]$ Because if you are going into a very complex product like this, $[\ldots]$ you realise that there will be situations where things are broken and we don't understand why. If you had only changed one variable, then you have got a fairly good shot at guessing what's broken and how to fix it. If you change a lot of variables then it becomes a very complex equation. (US project manager)

Sticking closely to the template also facilitated tracking and predicting the impact of any current and future changes. This objective was fuelled by fears of what short and long-term drift away from the original template might imply, both for the product and the organization. These fears were based on the experience of a previous product transition where processes had been allowed to drift significantly, with disastrous consequences for the product, the relationship between the sites and, ultimately, the viability of the transfer recipient.

What we heard of was that $[\ldots]$ they went off and engineered two different processes. The only thing they agree on is that the two products look the same when they come out of the factory. But [...] they are tested differently, I think the quality levels are probably different, and we didn't want that. (UK manager) Remember the discussion about the cycle time? They'd presented some cycle times, and we said: that's impossible. And they found out that, no, that was possible because people who had been trained in the 
test process decided to ignore it when it came time to ship the system [...] But you cannot ship a bad quality product to a customer. And so they shut them down. (US manager)

\section{Pressure for improvement}

While the pressure to copy exactly dominated the transfer, there were at the same time strong pressures to change and improve the template (Table 2). High-end servers are typically subjected to strong and constant pressures for both radical innovation (i.e. new architectures) and continuous improvement (i.e. faster micro-processors, or the adoption of industry standards and 'best practice') in order to retain a competitive edge. Agility (the ability to incorporate changes rapidly) and flexibility (the ability to change product, process and organizational configurations) are of crucial importance in this fast moving sector, as argued by a US manager: "We have to be quick on our feet, we have to be able to shift [rapidly] and [...] give the customers whatever they want".

Additional opportunities for innovation and improvement may also arise as templates become exposed to scrutiny by new sets of experts. In high technology transfers, as opposed to simpler cases such as food franchises, recipient sites are often as competent as the originator (although often in different areas). This generates immediate learning opportunities, as well as acute pressures for improving the golden formula following exposure to local knowledge and expertise.

They are frankly better than we are in their process. [Destination] is very regimented, they are very 'we have to do it by the book'. We are 'we have to do it and we'll do it any way that we have to'. So agility, flexibility and speed, rather than process. (US manager)

Destination was critical from the outset of the lack of process standardization at origin. They thought themselves as being more advanced in the way they performed and documented their practices.

First, you do things by heroics: people that are heroes, go in there and do whatever it takes (no matter how dirty) with the process [as in the case of the US site]. This works at the individual level. Then the next level is a procedure to do it. You know how you did it. This is at the project level. Third, not just having a procedure for doing one but a procedure for doing any framework on any products. This is at the process level. And fourth, there is a well-defined process, you know how to do it, take all that knowledge and apply it to all other cases [as it is done at the UK site]. So from heroics, to project, to process, to a well-tuned methodology. (UK diagnostics manager)

In addition, in contrast with the transfer originator which specialized in the one high-end product, the recipient was a multi-platform and multi-product site. They were experts in cross-products, crossplatform standardization, as well as being advanced adopters of global standards (i.e. ISO 9001, SixSigma). For example, they were able to promptly detect opportunities for making process and product more modular and therefore flexible. They could also foresee opportunities for enhancing 
process and product integrity by supporting international standards, which were instead perceived by origin as "a European thing" (UK process manager).

A further pressure for improvement was product maturity. In a fast moving sector such as high-end electronics, firms are often pressured to come out with new, more advanced products on a constant basis. Pressure to keep up with the competition means that often new products are pushed out the door before they are ready and therefore retain a number of maturity issues.

So there was a lot of pressure being felt at the senior management level to just deliver something. And so at the end they pushed it out the door, and we [origin] really had to do some amazing athletic manoeuvres to get a product tested [on time]. And so really in a well-engineered product you always have a few problems that are uncovered when you go to production, but this [...] is the most difficult product [we] had to bring to market" (US project manager)

Product immaturity created pressure for improvement, which was readily endorsed by engineers at destination who were able to identify scope for changes and did not fully comprehend or share the motivation behind copying exactly what in their view was an underperforming product.

In synthesis, the complex nature of the product and the template meant that the only way to transfer the product successfully was to copy it exactly. At the same time, however, there were some strong competing pressures from the outset that went against copy exactly, towards innovation, change, and improvement. How did those practitioners manage to realize their goal to copy exactly, despite the presence of such acute tensions pulling towards innovation?

\section{Role of artifacts and communities: orienting towards alignment}

The cornerstone of their replication strategy was to create and invoke a dedicated set of artifacts and communities that supported close alignment between routines at origin (template) and destination (Tables 3 and 4). This involved standardizing, that is reducing variation from the template by selectively allowing and supporting those views and actions which favoured alignment (i.e. by outlining how and how far to align) whilst disallowing and discouraging those which favoured improvement (i.e. by highlighting the dangers of losing alignment).

\section{Role of Artifacts: standardizing}

Artifacts created to support alignment included the 'Big rules', the 'Model', and the 'Exceptions List'. The 'Big Rules' were a set of conventions which played a key role in supporting alignment by dictating how far they had to align (and therefore how close they should be to the template). An imperative they devised early on, for example, was that the new product, process and organization had to mirror the template to the extent that even "the height of the technicians [counterparts] had to be the same" (UK manager). Another rule was known as 'blue screwdriver, red screwdriver': 
Our director said: 'You've got to transfer this exactly as we are transferring it, if we use red screwdrivers, you are going to use red screwdrivers, no matter what we do, you are to do it exactly the same' (ibid)

Similar rules instructed routines participants to 'cut and paste', or 'carbon copy' the original template at destination. Rules clearly indicated that only those views and actions that supported exact alignment would be acceptable, while anything else would be forbidden and condemned as even small changes from the template could escalate into a significant loss of alignment.

Overall, the Rules acted as a set of high-level imperatives which helped orient practitioners' views and actions towards the 'golden standard' (template). Another key artifact created in support of alignment was the Model, a central computer database containing highly detailed procedures describing how to align to the template. The Model consisted of a bundle of standard operating procedures which provided a single, codified, and standardized step-by-step description of the product and all related production routines and sub-routines. It was created by drawing on the product and process definition available from the central corporate database. Procedures were updated through direct observations and uploaded again on the common database which was shared with destination: "There is only one process $[\ldots]$ and it's pretty well controlled, documented. [...] [T]here is only one database and people see the same thing in all parts of the world $[\ldots]$ all the way to the field" (UK manager). The Model performed as the key reference point from which UK engineers could draw for the purpose of alignment. A final key artifact created to support alignment was the Exceptions List. In order for everything to be identical, any deviations from the Model had to be agreed, recorded, classified and controlled through a strict 'Exception Approval' methodology inspired by NASA.

What we have is an Exception [approval] Process whereby people have to detail exactly what the difference is, why it is there, the consequences it brings, and then it goes up to people where they say I approve this difference or I don't, allowing a minimal amount of change to creep in. Basically what we bring in are very well controlled and understood differences. (UK manager)

The Exception Process involved drafting a list of "[...] ninety [exceptions that we] chose to move either in [origin] or [destination] or both so that we could align" (US manager). Examples of exceptions included: Process (“Does this require a separate process document?"), Cost ("Does this drive a cost increase at either factory?") and Quality ("Does this cause a variance in product quality at any stage?”) (Internal Report). Exceptions were assigned priority levels: Level 1 status reflected global agreement (coded in colour green) and Level 2 was global disagreement and escalation (colour red). Levels were negotiated and attributed to one of two categories: 1- differences accepted (remain different) or 2- closed (aligned). The List acted as a key tool to reduce variation in both ostensive patterns and performances: "[Thanks to the list] we are going to be very in sync with them, almost identical" (UK manager). The list was also used to agree any permitted deviations from the template (those that had no impact over key variables): "Everybody has to be happy with the decision, which 
has to be well- understood and controlled. If a change has any impact at all [...] then it's not going to happen" (ibid). Together, the Big Rules, the Model and the List helped in preventing any significant deviations from the template, therefore progressively orienting actions and views towards alignment.

These powerful and sophisticated tools, however, were not infallible. No matter how thorough the efforts to specify rules (Blau 1955) there inevitably remained gaps in micro-level process definition "[...] things that don't have a second-by-second description of procedure" (UK manager) that defeated the attempts to fully codify the template. These gaps provided some opportunities for interpretation and deviation: "From that discussion, I don't hear anything that is red. It might not be green, but I don't see anything holding us up" (UK engineer). Pressures to change and improve despite - or perhaps even in reaction to - the emphasis towards alignment, provided frequent occasions for debate and dissent among participants. Most of these instances of deviation however, while marginally allowed to persist at the local level, were condemned in the context of global meetings and forums where transfer communities met up to compare and discuss their progress.

\section{Role of Communities: standardizing}

In addition to artifacts, organizational communities were created and invoked to support this monumental alignment effort. Similarly to artifacts, they supported alignment by standardizing views and actions, thereby eliminating any opportunities for variation from the template. They achieved this through promoting inter-site and inter-functional discussion and negotiation which adjudicated over the kind and extent of deviations. A joint inter-site committee was set up early on to provide unfailing support to this exacting transfer process. The community was meaningfully named 'Failure Is Not An Option' (FINAO), from NASA's Apollo 13 space mission, reflecting the importance of achieving perfect alignment. The FINAO community was made up of representatives of both sites in all the key functions (Manufacturing, Testing, Materials, Training, etc.). Participants met face-to-face each quarter, and held weekly teleconferences. In addition, counterparts liaised on email on a frequent, even daily basis.

So we invested in travel and relationships, knowing that in a project like this, separated by 10,000 miles and two different cultures that we were going to have disagreements and times of stress. And so you had the relationship, like a marriage, the good times allow you to go through the bad times. (US manager)

FINAO, supported by an Exceptions Review Board, provided a forum where any differences could be highlighted, brought up for discussion and decisions could be made as to whether they should be allowed (and tracked) or disallowed. Participants in FINAO meetings regularly discussed performances that appeared to be out of alignment and often negotiated among different possible understandings of the routine in question. 
When we had a question, when we heard a rumour, when we weren't sure of something, instead of stewing on it, gossiping about it and maybe reacting in a way that was not positive, we felt comfortable calling our counterparts on the phone and say 'Hey, I've just heard this, what do you know about this, can you check it out for me'. And someone up here would check it out. (US manager)

FINAO's material-discursive practices also provided an important means to verify possible sources of divergence and make people accountable for their actions: "These FINAO meetings create deadlines for us. It forces us to go off and do work because you know you're now face to face, you're over here, you are basically held accountable by your peers" (UK manager). In synthesis, communities encouraged practitioners to further orient their views and actions towards alignment.

This does not imply, however, that there was outright consensus. UK engineers, for example, saw early opportunities to improve the process by drawing on their experience as well as exploiting potential synergies between the sites. Participating in the FINAO and Review Board communities, nevertheless, helped orient views in favour of alignment by making team members aware of the implications of their actions for alignment as well as by subjecting them to scrutiny by different functions and levels of authority. The Engineering attempts to introduce improvements were often challenged during the course of FINAO meetings and dismissed, at least partially and temporarily:

The new factory is going to be effectively like another [origin site]. That is where the tensions arise. Because people say: well, I can see a lot of synergies if I do things the way other people are doing it elsewhere. You have to say ok, I can see that, but you can't do that yet. We want people to do this first [copy exactly] and [improving] is of secondary importance to actually doing it. (UK manager)

Pressure to copy exactly meant that 'being aligned' was more important than 'being ahead'. A striking example of this was how, following a heated debate, destination agreed to downgrade their procedures in order to align to the US template (which was not yet ISO compliant). So while small differences might have crept up at the lower process level, where engineers were locally improvising or experimenting in their sandbox, the Model, Rules, Exceptions List, FINAO and the Review Board together prevented these from proliferating and escalating to the level of the global organization. The combination of artifacts and communities provided a powerful device which favoured patterns of alignment while at the same time relegating any contrasting improvement patterns to the background.

At a future date we will talk about improving $[\ldots]$ but that will be in a year's time or more down the line, it is a matter of secondary importance. The most important thing is actually to build the product to great quality and in that sense that recipe has been validated in [the US]. (UK manager)

\section{Post-transfer}

The emphasis on alignment, however, was not to last indefinitely. The end of transfer was marked by an exacting testing process which confirmed the viability and statistical comparability of the 
transferred production capability and its outputs. The realization that the two production sites were able to achieve similar results (Winter et al. 2012) triggered an inversion in the original decision to support exact alignment. As participants in the transfer breathed a collective sigh of relief and celebrated their accomplishment, the support in favour of perfect alignment immediately began to waver. Arguments that up to that point had been sidelined, were now suddenly being voiced. Opinions that until then had been withheld began to find an audience.

At the beginning, there was paranoia to align everything. You could have changes but you would have to align the hell out of it. Now there is still a perception that we are every little bit aligned and that we know every little piece that is not, but we are not quite as worried as we used to be. (UK Project Manager)

Views and actions in favour of change and improvement began to gain focus and canvass support, while the rationale for copying exactly began to slowly but progressively shift into the background.

\section{Pressure for improvement}

Among the voices that were gaining strength was the urgent need for improvement (Table 2).

It should be alignment but I am not entirely convinced that we really know about the costs and risks of being completely aligned against not. Does it cost more money to be aligned just for the sake of it? Does it cost more money not to be aligned? Does it stifle creativity if you force two engineering groups in different parts of the world to copy one another? And we've got obstacles to change anything? (UK manager)

Even US engineers, who had initially felt irritated by the UK's condescending attitude towards the product "Yes, yes, I understand, [but] we can make it better", as well as threatened that changes introduced at the UK end would imply loss of control on their part, were now beginning to acknowledge the need for improvement. The urgent need for product and process improvement that was sorely felt, due to product immaturity issues that had followed its rushed introduction to market, could now be implemented. This argument was relayed by a UK Engineering Manager:

There has been an emphasis on policing and a very negative way of doing things. Rather than sharing information about best practice type of thing. I think that rather than focusing on being identical we should focus on moving the product and the process forwards and getting best practice to engineering. Enforcement should not be necessary. Here you are forced not to do best practice.

The rationale in favour of change was the ability to finally make use of the local engineering expertise. 'This issue 'we can do better than [origin]' was there from the beginning - and it is still there. Engineers, when they work, they want to do the best that they can" (UK Engineer). The expertise of UK engineers, at last, could be invoked: "These guys have got some great ideas and we shouldn't shun them, it doesn't make us necessarily look bad, it just shows evolution" (US Manager). And also, 
[it would be wrong to continue] to force (destination) to be our junior partner [...] to communicate to them that they have nothing to add, that basically their job is to take what we have given them and just build it. In this case [not only] you'd have a mindless set of slaves that [are] going to sabotage it, but also you are not encouraging any innovations and not making use of those people. (US Project Manager)

Arguments that advocated the need to introduce global standards were also being voiced forcefully: "With transition they think [destination] should copy everything. But there is a need to globalize" (UK Project Manager). The imperative to comply with origin procedures for the sake of alignment, even when it forced destination site to downgrade to non-ISO compliant procedures, was now no longer deemed acceptable.

Processes at (destination) are ISO approved but not those at (origin). The picture at (origin) is very much like a Rolls Royce manufacturing site. All they do is to make that system. And they [...] do a very good job, but they never had to embrace the challenge of doing multiple products. [...]There is a lot of tension around [...] "where's that written down?" "Well, Bob knows it, Bob's always done that job". That's not the way ISO works. [ISO means] having repeatable, sustainable processes. That's the tension, the dangerous thing. (UK process manager)

\section{Pressure for alignment}

While innovation was rapidly taking hold, pressures to replicate persisted in the background (Table 2). Despite acknowledging the impossibility to maintain the expensive (and now mostly redundant) alignment infrastructure in the long term, the US team felt uneasy about the prospect of drift and the inevitable loss of control over the template which they had enjoyed so far. The dangers of drift between product and process definition at the two sites had been clearly captured in the earlier discussions about the previous transfer, where the loss of alignment had ultimately caused the recipient site to be shut down. Memory of this tragic closure of a historic US site was still very much present in the transfer teams' consciousness, especially on the American side. In addition, the fear of finally relinquishing control over their cherished invention by allowing the UK team to make changes to product and process specification was difficult to accept for the US counterparts. How did the pressure to improve manage to prevail despite the US reluctance to let go of alignment?

\section{Role of artifacts and communities: orienting towards improvement}

A new array of artifacts and communities was created and invoked at this stage to introduce changes to the template while at the same time providing reassurance that innovation did not imply a total loss of control over product and process. The new artifacts and communities provided a - careful but decisive - response to the ever-present, relentless pressures for innovation, improvement, and adaptation which had been frustrated under the unforgiving copy exactly regime (Tables 3 and 4). During post-transfer, artifacts and communities helped orient views and actions towards improvement by orchestrating changes. This involved progressively increasing variation from the template by 
selectively allowing those views and actions which favoured improvement (i.e. by helping to verify the impact of proposed changes on existing processes and procedures) whilst reducing the emphasis on exact alignment (i.e. by advocating the benefits of improving, adapting, innovating).

\section{Role of artifacts: orchestrating}

The shared Model created during transfer to support alignment remained a key tool during posttransfer, but it was modified to support variation from and improvement to the original template. If until now the Model had been 'frozen' to encourage or even force engineers to copy exactly the US specification, now it was 'unfrozen', or modified, to allow the introduction of changes to the embedded standardized routines that make up the codified version of the template. This, for example, involved changing the Model to reflect any procedural changes required to align to global ISO standards, or to facilitate the introduction of ad-hoc engineering improvements. A UK Process Manager explained that "currently processes are changing rapidly, for example manufacturing is at the $\mathrm{K}$ version of the process. [We have] moved on [rapidly] from one revision to the next with the aim to achieve a global level". New artifacts were also created post-transfer to support the controlled introduction of changes to the production process and related sub-routines. The Engineering Change Request (ECR) tool, for example, was introduced to facilitate the introduction of innovations:

[...] and now we are really saying: ok, how do we get continuous improvement out of the [destination] team? Well, we have to develop a structure that allows people to innovate, and then through the change management process say, here's a great idea, why don't we implement this at both sites. And then they have to have a two-site conversation, agreeing that, you know, that's a great idea, what do we have to do to implement it. (US manager)

The tool allowed teams and functions to share information about and visualize proposed changes before they were implemented, thus predicting their potential impacts:

Our view is, maybe you don't get the support of all the cross-functional operations but you get awareness, everybody to know what is going on outside their own area [...] A cross functional team is supposed to share that information [such as] if we do x, what would that mean, what do you think. (UK manager)

\section{Role of communities: orchestrating}

In addition to artifacts, organizational communities were created and invoked to support improvement by promoting the concerted introduction of changes. They achieved this through creating and mobilizing discussion forums where practitioners could discuss any proposed changes and verify their relevance and fit with existing routines. A new inter-functional community, the Change Review Board (CRB), was created to predict the impact of and monitor changes: 
It's just a matter of assessing the impact to the different groups of that change request. Maybe that means that everybody sees that there is a change request, but who needs to be aware of that, who needs to approve it. That's what the Change Review Board is supposed to do. (UK manager)

The inter-functional Board meetings provided opportunities for discussing, reviewing and negotiating changes.

The [CRB] meetings are actually even more important than the tool itself, we have a good crossfunctional representation there, and greater visibility of what engineering is thinking about changing which is also helping them to understand the cross-functional impact of that. (UK manager)

In addition to creating new communities, existing communities which had been so far marginalized were now allowed to dominate the discussions. Among the voices now gaining traction was that of the Engineering Forum community, whose goals had been originally seconded to the goal of alignment:

[Other companies] don't have the same desire to be identical. They have the desire to have the same product going out the door, and the desire to have best practice in engineering so they do a lot of sharing of ideas and information but then it is up to the individual sites and engineering to determine these are best for the site and those are not [...] That way both sites are not identical but they get the best from two different groups of engineers. (UK manager)

This view was becoming increasingly popular with the UK Engineering Management community, which throughout the transfer had supported Copy Exactly, but was now beginning to endorse an engineering vision involving a much looser form of alignment. Such vision was debated and consolidated during the course of Engineering Forum meetings and made material though the rewriting of the Model which was being modified to incorporate changes in procedures that favoured improvement. Following the introduction of new artifacts and communities and their painstaking efforts to improve the template, pressures for alignment were progressively sidelined. The FINAO team at this stage was disbanded, having accomplished its main goal of delivering a statistically verifiable replica of the original template.

The path away from alignment and towards improvement, however, was not devoid of obstacles. In reaction to the disbanding of FINAO, as well as to the fears generated by the prospect of a complete loss of alignment and control over the template, US Project Management devised a new tool. Site process Audits consisted of members of the US team travelling to the UK to verify the actual extent of alignment in the main routines and subroutines as they were performed. Audits, however, were viewed negatively by the Engineering community as a further, and at this point rather ineffectual, attempt at policing performances at destination. Bureaucratic and expensive to carry out, and perceived by engineers as "a witch hunt, $[\ldots]$ something that reflects poorly on [teams], and individuals", audits proved difficult to endorse, especially in the absence of FINAO. 


\section{A framework for enacting contrasting organizational goals and pressures}

The evidence above illustrates how routines participants attempted to balance replication and innovation, and the related pressures to align and improve, during the course of a complex routines transfer. By drawing on a dynamic view of routines (Feldman and Pentland 2003) these findings extend the replication perspective on routines transfer (Winter et al. 2012) while adding to the Carnegie's account of goal balancing (March 1991, Cyert and March 1992, Levinthal and March 1993) by theorizing how organizations address the innovation/replication dilemma through dynamically enacting contrasting goals and the associated pressures. The theoretical framework in Figure 2 illustrates the main findings by articulating the micro-level, sociomaterial dynamics enacted by routines participants in their attempt to balance competing pressures and the role of routines in managing multiple goals.

As the framework illustrates, in order to reconcile contrasting pressures towards innovation and replication, organizational members simultaneously created and maintained two ostensive patterns, one in favour of alignment (supporting copy exactly, or replication) and one in favour of improvement (supporting change, or innovation). Building on Turner and Rindova (2012) I name these patterns of targeted alignment and improvement. The alignment and improvement ostensive aspects were used for guiding, accounting and referring to (Feldman and Pentland 2003) alignment and improvement performances. Specifically, participants in routines transfer used the ostensive patterns as follows: first, prospectively, as a guide to what actions ought to be taken in order to support alignment or improvement (i.e. "we need to perform this step in order to align to the template"; or "we need to change this sequence in order to improve the template"). In so doing, they acknowledged the need for alignment or improvement, as well as highlighting any potential obstacles or opportunities. Second, retrospectively, as a guide to accounting for actions already taken to support alignment or improvement (i.e. "we have done this to align to the template"; or "we changed that process to improve the template"). Third, they used the ostensive to signify or refer to what is similar or dissimilar about a set of performances (i.e. "these action sequences are aligned, not aligned or partially aligned to the template"). In response to pressures for copy exactly or change, routines participants enacted each of the alignment or improvement patterns selectively through a dedicated set of artifacts and communities, encouraging the emergence of alignment or improvement performances.

In particular, during transfer, routines participants created and nurtured the ostensive alignment pattern which supported alignment/replication while relegating improvement to the background. Participants achieved this by performing routines through dedicated sets of artifacts (Model, List, Rules) and communities (FINAO, Project Management) which favoured alignment over improvement. I name these alignment performances. Artifacts and communities at this stage helped orienting towards alignment through supporting alignment work. This involved standardizing, 
reducing variation across views and actions in order to favour alignment and minimize, or wherever possible eliminate, any differences from the template. In turn, alignment performances enacted and supported the alignment ostensive pattern therefore further orienting routines towards alignment.

There were two related mechanisms which helped reduce variation from the template: inscription and affordance. Inscription (Akrich 1992, Latour 1992) is the process by which actors delegate knowledge and goals (i.e., innovation, replication) to artifacts during their design and usage stages. The Model, List, and Rules, for example, were created and implemented with the aim to support actions and views that favoured alignment. The artifacts' material properties, however, were not fixed. Their actual affordances (Gibson 1979, Hutchby 2001), or "possibilities for goal oriented action afforded to specific user groups by technical objects" (Markus and Silver 2008:622) were constantly redefined by actors through subsequent negotiations. Negotiations took place in 'hybrid forums' (Latour 1987) where communities of practitioners traded over different perceptions of the artifacts' affordances and constraints, and their implications for alignment or deviation.

The List, for example, was designed for the purpose of standardizing and aligning views and actions across sites. It helped reduce deviation from the template by allowing actors to identify, list and compare exceptions while also tracking their progress. The actual extent of alignment and cross-site standardization afforded by the List, however, were relational and context dependent (Hutchby 2001) and depended in part on negotiations taking place during FINAO meetings. The meetings, for example, helped decide whether actions and views were aligned and, if not, how differences could be eliminated. This included debating and aligning different interpretations of the actions' content, sequence or status (i.e., is this action 'green' - fully aligned - or 'yellow' - almost aligned) by different participants.

The influence of artifacts and communities, however, was not complete. While these helped orienting towards alignment, there were nevertheless some actions and views that escaped their influence. This was the case of the engineering community which, frustrated by the inability to use their expertise to improve the template began to introduce some minor modifications (i.e. rewriting small fragments of code, introducing minor step changes to standard codified sequences). The combined influence of artifacts and communities, however, ensured as far as possible that contrasting improvement-oriented views and actions were not allowed to propagate beyond the local level (i.e. the engineering function). As a result, the emphasis during transfer weighted heavily in favour of alignment/replication, while improvement/innovation was pushed into the background.

During post-transfer, participants enacted a different ostensive pattern favouring improvement, which supported improvement/innovation, while relegating alignment/replication to the background.

Participants supported this pattern by performing routines through another dedicated set of artifacts (Revised Model, Change Management Request) and communities (Change Review Board, 
Engineering Forum) which favoured improvement over alignment. I name these improvement performances. Artifacts and communities at this stage helped orienting towards improvement through supporting improvement work. This entailed orchestrating, that is encouraging variation across views and actions by facilitating the incremental introduction of changes to the template. Changes included product and process innovations, continuous improvement, and alignment to global company- or industry-wide standards (i.e. ISO 9001, Six Sigma). In turn, improvement performances enacted and supported improvement ostensives thereby further orienting routines towards improvement.

As before, inscription and affordance negotiation were key mechanisms at play in supporting improvement. The ECR tool, for example, was conceived to increase variation by orchestrating changes. This involved allowing actors to visualize and share information about changes and their impacts, thus facilitating their introduction. Again, the extent of variation afforded by the tool depended in part on the CRB and Engineering Forum meetings where practitioners negotiated the feasibility of proposed changes and their potential inter-functional impacts (i.e. why is this screw gold when it should be silver?). Also in this case, the influence of artifacts and communities was not complete and generated some contrasting effects. Residual pressures in favour of alignment remained present and were harnessed by functions (US Project Management) which in reaction created and invoked artifacts (Audits) in an attempt to rein performances back towards alignment. Due to the disbandment of FINAO and the partial re-orienting of the UK management community towards improvement, however, the relative deviations uncovered through local process audits were no longer prosecuted and mostly remained un-acted upon. As a result, innovation prevailed, while replication was consigned to the background.

\section{Enacting competing goals: from sequential attention to selective performance}

The above evidence shows that replicating routines in the presence of contrasting goals is ultimately related to how transfer participants manage competing pressures, both at specific points in time and over time. In the case examined here, I found that routines participants were able to address simultaneous pressures for innovation and replication by creating and nurturing two different sets of ostensive patterns and performances, one supporting alignment and one improvement, which they enacted in different proportions. They did so by performing routines through selective configurations of artifacts and communities that alternatively supported one pattern or the other, by allowing specific knowledge, views and actions to be foregrounded at the expense of others. While the contrasting patterns of alignment and improvement were not eliminated but persisted in the background, enacting routines through selective sociomaterial configurations allowed emphasizing one goal while simultaneously managing the residual conflict. Over time, as exogenous or endogenous pressures shifted, the organization was able to dynamically switch emphasis from one goal to another. 
I name selective performance the process by which organizations harness social and material features of context to enact routinized patterns which selectively perform one goal over another, both at specific points in time, and over time. This mechanism helps explain how organizations may be able to manage contrasting goals simultaneously while also dynamically switching emphasis across goals over time. In this case, routines participants created and invoked a set of artifacts and communities to selectively perform, or favour, replication, and then innovation. Thus, as transfer began, they were mostly exploiting/replicating, while at the same time innovating at the margin; whereas, later on, they were mostly exploring/innovating, while replicating at the margin. In other words, they were enacting patterns of actions and ostensive patterns which first selectively favoured replication (alignment) over innovation, and then selectively favoured innovation (improvement) over replication.

Overall, these findings shed new light on the innovation/replication dilemma in routines transfer while also making key contributions to wider topics in organizational and routines theory. These include how organizations unravel the replication dilemma in routines transfer, the role of routines in enacting contrasting goals, and the role of artifacts and communities in the reproduction of routines.

\section{Conclusions}

\section{Performing the Replication Dilemma in Routines Transfer}

How organizations address the replication dilemma is an important but so far neglected aspect of the scholarly discussion around routines transfer. While the tension between innovation and replication has been recognized as being a key feature of transfer (Winter 2010, Winter et al. 2012), there remains a gap in theorizing how this trade-off is managed. The current assumption is that competing demands for innovation and replication are attended to in an orderly sequence (exploration, followed by exploitation, again followed by exploration) (Winter and Szulanski 2001). This high-level predicament, however, is by no means incompatible with the finding that, at a more micro-level, contrasting tensions coexist and challenge routines before, during transfer and beyond. In this study I have shown how conflicting pressures for replication and innovation manifestly persist throughout the transfer, despite clear attempts to defer in time, while also theorizing how they shape routines and the underlying truces (Nelson and Winter 1982). In so doing, I have articulated how routines participants attempt to balance contrasting pressures by harnessing social and material features of context. The main contribution of this paper is therefore to draw from the 'routines as dynamic systems' approach (Feldman and Pentland 2003) to generate a framework that captures the dynamic, micro-level and sociomaterial processes by which organizations unravel the replication dilemma by learning to simultaneously address contrasting goals and the ensuing tensions. 


\section{The role of routines in enacting contrasting goals}

This takes us to a second core finding, concerning the role of routines in enacting competing goals. Organizational scholars (Cyert and March, 1992) have introduced the notion of sequential attention to capture how organizations may be able to 'resolve' the issue of conflicting goals and tensions, such as exploration and a exploitation (March 1991), by focusing on one goal at a time, while deferring the other. While affording considerable insight into goal balancing, however, this notion is based on the assumption that organizations see, or experience, only one set of demands at a time (ibid). In contrast, this case highlights how organizations may be regularly and manifestly exposed to more pressures simultaneously. The concurrent presence of multiple, competing pressures implies that conflict often remains visible, despite attempts to defer in time.

I have introduced the notion of selective performance to explain how organizations harness routines to enact conflicting goals and pressures (i.e. innovation/replication, exploration/exploitation) at specific points in time and over time, while managing the residual conflict. Specifically, I observed how routines participants, simultaneously confronted with contrasting goals, first selectively performed one goal, and then the other. Through materially-mediated performances, they energized one goal (which was made more prominent), while backgrounding the other (which was not however entirely suppressed as in sequential attention). The evidence suggests that the high-level outcome of selective performance may not be dissimilar to sequential attention: organizations appear to mainly focus on one goal, then the other. Upon closer inspection, however, findings reveal the sophisticated microlevel mechanisms that help organizations selectively perform (enact, rather than simply pay attention to) contrasting goals simultaneously, while avoiding the decision-making 'freeze' which we would otherwise expect to occur in the presence of open conflict (Simon 1955, Ethiraj and Levinthal 2009). While therefore at the aggregate level routines participants appear to be balancing goals (either/or), at the micro level it is clear that they are selectively patterning (enacting both selectively).

Departing from sequential attention's focus on stability and balance, selective performance therefore emphasises the continuous, dynamic and reciprocal adaptation among different goals, where stabilization around one common objective may be sought but is rarely (and then only partially and temporarily) achieved. Selective performance might thus resemble an evolutionary engine (Nelson and Winter 1982, Van de Ven and Poole 1995) in reverse, involving cycles of selective retention (where actions supporting one goal are translated into patterns) followed by variation (where some actions elude selection or arise as a consequence of it), with some episodic change (where the emphasis shifts from one goal to another), but with a crucial difference. In contrast with an evolutionary motor, this mechanism is operating at the level of specific performances, thus drawing attention to features of context and the mechanisms through which actions are produced (Pentland et al. 2012). This points to a further key contribution of this study which, by drawing on routines dynamics, is able to reveal the effortful (Pentland and Rueter 1994) and emergent (Feldman 2000) 
'patterning work' that is involved in the constantly challenged and never fully achieved (Tsoukas and Chia 2002) pursuit of balance between competing goals.

While adding to the Carnegie approach to conflicting goals by providing a more dynamic explanation which accounts for the manifest coexistence of competing tensions, the above findings also raise important questions with respect to the supposedly incompatible nature of exploration and exploitation activities (Gupta et al. 2006). This leads to further insights into the kind of routines that may be required to harness contrasting goals. In particular, the evidence appears to challenge the established wisdom that strategies used by firms to manage exploration and exploitation, including spatial (ambidexterity) or temporal differentiation (sequential attention) require almost diametrically opposed routines, mind frames and processes (March 1996, Benner and Tushman 2003). In contrast, this study highlights the similar routines - and their subtly differentiated enactments - which organizations invoke in their effort to simultaneously address exploration and exploitation. This finding responds to recent calls for "more dynamic perspectives on ambidexterity" (Raisch et al 2009: 693) while also substantiating the proposition that "stability and change in different units and hierarchical levels" are not inconsistent but may instead "intertwine and depend on common practices" (Farjoun 2010: 218).

\section{The multiplicity of the ostensive and performative aspects}

This study also adds to the focal discussion around the multiplicity of the routines ostensive and performative aspects (Feldman 2000, Feldman and Pentland 2003, Howard-Grenville 2005, Zbaracki and Bergen 2010, Rerup and Feldman 2011, Turner and Rindova 2012). Findings show how, in addition to individuals (Feldman 2000, Howard-Grenville 2005) and connections (Feldman and Rafaeli 2002, Turner and Rindova 2012), organizational collectives, including occupational and practice-based communities (Brown and Duguid 1991, Lave and Wenger 1991) and their artifacts (Carlile 2002, Bechky 2003) can be harnessed effectively to help orient and re-orient ostensive patterns and performances towards supporting different organizational goals.

I find that enacting the same action sequence through different sets of artifacts and communities supported multiple, and even contrasting ostensive patterns which, in turn, fulfilled different organizational goals. During the course of transfer, for example, a set of artifacts and communities encouraged the emergence of alignment ostensives, which supported replication. The UK Engineer's goals were thus (partially and temporarily) reoriented towards alignment through adopting the Model and participating in the FINAO community. During post-transfer, another set of artifacts and communities encouraged the emergence of improvement ostensives which supported innovation. The UK managers' goals were thus (partially and temporarily) reoriented towards improvement, through participating in the rewriting of the Model and the Engineering Forum community. This finding builds on and adds to recent advances in routines theory by showing how performances enacted through 
different ensembles of artifacts and communities may not always or permanently generate a single, shared and overarching ostensive pattern (Dionysios and Tsoukas 2013) or goal (Zbaracki and Bergen 2010, Turner and Rindova 2012), but may instead give rise to multiple and even competing goals and patterns. This suggests that multiplicity tends to persist and defy coordination to an even greater extent than allowed in the extant routines literature.

Findings also show how enacting the same action sequence through the same set of artifacts and communities could support the emergence of different, and even contrasting, performances (in this case, at the margin). During transfer, for example, not all actions were successfully oriented towards alignment by the Model and the FINAO community. Gaps in process definition within the Model allowed for the emergence of conflicting improvement performances, following the UK Engineers' reaction to the excessive pressure to align. During post-transfer, the strong emphasis on innovation supported by the Engineering Forum and its tools prompted US management to create Audits in an attempt to rein performances back in towards alignment. While orienting performances towards a common goal, artifacts and communities could therefore also generate the opposite effect at the margin. These findings both confirm and extend our understanding of the multiplicity of the routines performative aspect (Howard-Grenville 2005) by showing how different ostensive patterns may not always or completely be coordinated into the same performances but may sometimes give rise to different, and even conflicting performances. In drawing on a fine-grained approach to transfer informed by recent advances in routines and practice theory, and relinquishing a view of routines as stable and discrete entities (Feldman and Orlikowski 2011), these findings therefore contribute a more dynamic perspective on the role of context in routines transfer while also responding to recent calls for understanding multiplicity in routines (D'Adderio et al. 2012).

\section{The role of artifacts and communities in the reproduction of routines}

Finally, the evidence above confirms recent advances on role of artifacts (Pentland and Feldman 2008, D'Adderio 2008 and 2011, Turner and Rindova 2012) and communities (D'Adderio 2008 and 2011, Zbaracki and Bergen 2010) in the transfer and reproduction of routines, while at the same time extending earlier findings in several promising directions.

A first consideration concerns how routines relate to their (social and artifactual) context. This issue has been discussed under the heading of 'embeddedness' (Granovetter 1985), a notion which has been used in routines theory to explain how the organizational context provides structures within which ostensive views are shaped and performances take place (Cohen et al. 1996, Howard-Grenville 2005). The above findings highlight a crucial feature of embeddedness which has been so far insufficiently emphasized: rather than performing as a fixed background for routinized action which precedes action, context contributes to dynamically constituting and reconstituting routines. This implies that routines are not simply embedded in context, they are also enacted through context. They change 
dynamically as they are enacted through specific configurations of artifacts and communities which shape ostensive and action patterns leading to varying outcomes (i.e. alignment or improvement, replication or innovation). Context itself may also change dynamically as artifacts and communities are transformed through being involved in routinized performances (i.e. new or modified communities and artifacts may be created and invoked to support new or revised goals).

An important contribution of this study for routines theory is therefore showing how routines and their social and material context are mutually and dynamically constituted (Feldman and Orlikowski 2011) through enactment. In this sense, replication is not simply about the reproduction (as in the Carnegie approach) but also about the effortful recreation of a routine in and through a different context. By illustrating the close ontological connection between practices and their context (ibid), this study also adds to practice theory by showing how specific assemblages of artifacts and communities can be dynamically enacted as resources to shape routines and harness multiple goals. This resourcing process (Feldman 2004) helps capturing how different sociomaterial or socio-technical (Suchman 2007, D'Adderio 2008 and 2011) configurations can be invoked to enact different routine patterns that support different goals, at different times.

This raises the question of precisely how social and material features of context configure routines and contribute towards fulfilling multiple objectives. I have introduced the notions of inscription and affordance to explain how goals may be delegated to artifacts, and become subsequently reshaped through enactment and participation in organizational communities. This not only implies that organizational members may be able to create and modify artifacts to support their goals and preferences, but also that the latter in turn may evolve as actors become engaged in performances involving new or modified artifacts and communities. This finding sheds light over the intrinsically sociomaterial character of routine-following, thus enriching the Carnegie explanation of routines transfer (Winter and Szulanski 2001) and goal balancing (March 1991, Cyert and March 1992, Levinthal and March 1993). In showing how individual goals and interests are reshaped through performances, this finding also illustrates how the actors' preferences are rarely stable, as often assumed, but are instead dynamically constituted and reconstituted through their socially- and materially-mediated participation in routines.

A final important implication of the above theorizing is that it supports a novel and more dynamic characterization of artifacts and their properties than allowed in the extant routines theory. The evidence thus shows how artifacts themselves are not flexible or inflexible in absolute terms. Rather, their properties and affordances are always emergent and often contested, and can be dynamically altered through (re)design and subsequent enactment to support change or consistency (in this case with respect to the template). This, for example, was the case of the Model, which was modified during the course of the transfer, first to support replication and then innovation with substantial 
consequences for routine alignment. This finding adds to the extant routines research concerning the role of artifacts in supporting change and consistency (Pentland and Feldman 2008, D'Adderio 2008, Turner and Rindova 2012), while also responding to recent calls for a deeper understanding of the nature and role of artifacts in the design of routines (Turner and Rindova, ibid).

In extending the current understanding of the role of context in the (re)creation of routines, this study thus contributes a much needed sociomaterial explanation to how organizations enact multiple goals while addressing contradictions (Adler et al. 1999, Ethiraj and Levinthal 2009) as well as contributing to the literature on routines transfer (Winter and Szulanski 2001, Winter et al. 2012) by theorizing the role of routines dynamics in helping unravel the replication dilemma.

\section{Boundary conditions and directions for future research}

In capturing the interplay between innovation and replication at a multi-site, high-innovation and high-technology organization undertaking a complex transfer, this study has provided fertile terrain to explore how organizations address multiple, conflicting objectives in the short term and over time. In departure from the Carnegie approach which, despite affording considerable insight into routine transfer and goal balancing, has relatively emphasized stability over conflict, this study has highlighted the highly unstable and constantly challenged coexistence of contrasting goals and its consequences for the organization. This holds some important implications which at least partially span beyond the scope of this paper, thus providing opportunities for future research.

A first observation is that, once we focus on conflict and instability, rather than truce and stability, we can begin to see how any apparent balance between conflicting goals must always and necessarily be partial, temporary and precarious. In favouring stability over conflict (the unstable and constantly challenged coexistence of exploration and exploitation), the Carnegie approach has only captured one possible outcome (when one goal prevails, then the other) out of an entire possible range (i.e. where neither innovation nor replication prevails, or where innovation or improvement to the template may precede replication, despite the negative implications that this might bear, as Winter et al. have convincingly argued and as indeed confirmed here by the example of the previously failed transfer where drift eventually caused the site to be shut down). This implies that, at least in principle, any goal can prevail at any stage, without following a preconceived order. In addition, anything can, again in principle, contribute to alter the relative balance between goals, thus causing the switch from one prevailing goal to another. While this study has theorized the social and material dynamics through which goals may be alternatively foregrounded, future research is required to characterize the microlevel dynamics by which goals confront one another.

A further observation that stems from the above discussion is that the extent to which goals may be conflicting is not absolute but context dependent. Thus the simultaneous presence of different goals, at different times, in different organizations can lead to very different outcomes. For example, 
innovation and replication might not always be conflicting in the same way or to the same extent as outlined here. Organizations of lower complexity operating in slower technological and/or innovation environments, for instance, might perceive innovation and replication as being at least partial complements, not substitutes. This might also be the case for organizations in high-innovation but lower complexity or reliability contexts. These might decide to introduce innovations and improvements at earlier stages of transfer, despite clear incentives to withhold changes to the template until this has been successfully replicated (Winter et al. 2012). Future studies should focus on how the replication dilemma unfolds for different organizations in less- and differently-demanding settings.

Finally, the extent to which goals may be conflicting or complementary tends to change over time. Replication, for example, can be seen as complementary to innovation from a longer-term perspective, as it provides the means for a firm to copy its innovations and therefore reap the rewards ahead of its competitors (Winter 2010). This suggests, more in general, that the relationship between goals may shift between contrasting and complementary over time as organizational, technological, institutional and environmental conditions also change. Together with the issues highlighted above, this finding suggests the need for a new stream of studies which may help extend and enrich the dynamic, micro-level, sociomaterial agenda on routines transfer and replication set out in this paper.

\section{References}

Adler P. S., B. Goldoftas, D. I. Levine. 1999. Flexibility versus efficiency? A case study of model changeovers in the Toyota production system. Organ. Sci. 10(1) 43-68.

Akrich M. 1992. The De-scription of Technical Objects. W. E. Bijker and J. Law (eds.) Shaping Technology/Building Society - Studies in Sociotechnical Change, Cambridge, MA: MIT Press.

Argote L., E. Darr. 2000. Repositories of knowledge in franchise organizations: Individual, structural and technological. G. Dosi, R.R. Nelson, S.G. Winter eds. The Nature and Dynamics of Organizational Capabilities. Oxford University Press, New York 51-68.

Argote L., P. Ingram. 2000. Knowledge transfer: A basis for the competitive advantage of firms. Organ. Behav. Human Decision Processes 82(1) 150-169.

Bartlett C.A., S. Ghoshal. 1989. Managing Across Borders: The Transnational Solution. Harvard Business School Press, Boston.

Bechky B.A. 2003. Sharing Meaning Across Occupational Communities: The Transformation of Understanding on a Production Floor. Organ. Sci. 14(3) 312-330.

Benner M. J., M. L. Tushman. 2003. Exploitation, exploration, and process management: The productivity dilemma revisited. Acad.Management Rev. 28 238-256.

Birnholtz J.P., M.D. Cohen, S.V. Hoch. 2007. Organizational Character: On the Regeneration of Camp Poplar Grove. Organ. Sci. 18(2) 315-332.

Blau P. 1955. The Dynamics of Bureaucracy. University of Chicago Press, Chicago.

Brown, J. S., P. Duguid. 1991. Organizational learning and communities-of-practice. Organ. Sci. 2(1) 40-57.

Carlile, P. 2002. A pragmatic view of knowledge and boundaries: Boundary objects in new product development. Organ. Sci. 13: 442-455. 
Carlile P.R. 2004. Transferring, translating, and transforming: An integrative framework for managing knowledge across boundaries. Organ. Sci. 15(5) 555-568.

Cohen M.D., R. Burkhart, G. Dosi, M. Egidi, L. Marengo, M. Warglien, S.G. Winter 1996. Routines and Other Recurring Patterns of Organisations: Contemporary Research Issues. Ind Corp Change 5 653-698.

Cyert R. M., J. G. March. 1992. A Behavioral Theory of the Firm. Blackwell, Cambridge, MA (originally published in 1963).

D'Adderio L. 2008. The performativity of routines: Theorising the influence of artefacts and distributed agencies on routines dynamics. Res. Policy 37(5) 769-789.

D'Adderio L. 2011. Artifacts at the centre of routines: Performing the material turn in routines theory. J. Inst. Econom. 7(2) 197-230.

D'Adderio L., M.S. Feldman, N. Lazaric, B.T. Pentland. 2012. Call for Papers-Special Issue on Routine Dynamics: Exploring Sources of Stability and Change in Organizations. Organ. Sci. 23(6) 1782-1783.

Darr E.D, L. Argote, D. Epple. 1995. The Acquisition, Transfer, and Depreciation of Knowledge in Service Organizations: Productivity in Franchises. Management Sci. 41(11) 1750-1762.

Dionysios D., H. Tsoukas. 2013. Understanding the (Re)creation of Routines From within: A Symbolic Interactionist Perspective. Acad. Management Rev. 38(2) 181-205.

Eisenhardt K.M. 1989. Building Theories from Case Study Research. Acad. Management Rev. 14(4) $532-550$

Ethiraj S. K., D. Levinthal. 2009. Hoping for A to Z while rewarding only A: Complex organizations and multiple goals. Organ. Sci. 20(1): 4-21.

Farjoun M. 2010. Beyond dualism: Stability and change as a duality. Acad. Management Rev. 35(2) $202-225$.

Feldman M.S., 2000. Organizational routines as a source of continuous change. Organ. Sci. $11611-$ 629.

Feldman M.S. 2003. A performative perspective on stability and change in organizational routines. Ind. Corp. Change 12 727-752.

Feldman M.S. 2004. Resources in emerging structures and processes of change. Organ. Sci. 15(3) 295-309.

Feldman M.S., B.T. Pentland. 2003. Reconceptualizing organizational routines as a source of flexibility and change. Admin. Sci. Quart. 48 94-118.

Feldman M., W. Orlikowski. 2011. Theorizing Practice and Practicing Theory. Organ. Sci. 22 (5) 1240-1253.

Feldman M.S., A. Rafaeli. 2002. Organizational routines as sources of connections and understandings. J. Management Stud. 39(3) 309-331.

Gibson J.J. 1979. The Ecological Approach to Visual Perception. Boston, MA: Houghton Mifflin.

Glaser B., A. Strauss. 1967. The Discovery of Grounded Theory: Strategies of Qualitative Research. Wiedenfeld \& Nicholson, London.

Granovetter M. 1985. Economic Action and Social Structure: The Problem of Embeddedness. American J. of Soc. 91(3) 481-510.

Gupta A.K., K.G. Smith, C.E. Shalley. 2006. The interplay between exploration and exploitation. Acad. Management J. 4 693-706.

Howard-Grenville J.A. 2005. The persistence of flexible organizational routines: The role of agency and organizational context. Organ. Sci. 16(6): 618-636.

Hutchby I. 2001. Technologies, Texts and Affordances. Sociology 35 (2) 441-456

Iansiti M., J. West. 2003. Experience, experimentation, and the accumulation of knowledge: the evolution of R\&D in the semiconductor industry. Res. Policy 32 809-825. 
Jensen R.J., G. Szulanski. 2007. Template use and the effectiveness of knowledge transfer. Management Sci. 53(11) 1716-1730.

Langley A., H. Tsoukas 2010. Introducing 'Perspectives on Process Organization Studies'. T. Hernes \& S. Maitlis (Eds.) Process, Sensemaking, \& Organizing. Oxford: Oxford University Press, 1-26

Latour B. 1987. Science in Action. Harvard University Press, Boston.

Latour B. 1992. Where Are the Missing Masses? The Sociology of a Few Mundane Artefacts. W. E. Bijker and J. Law (eds.), Shaping Technology/Building Society: Studies in Sociotechnical Change, Cambridge, MA: MIT Press 225-258.

Lave J., E. Wenger. 1991. Situated Learning: Legitimate peripheral participation. Cambridge University Press, Cambridge.

Levinthal D.A., J.G. March. 1993. The Myopia of Learning. Strategic Management J. 14: 95-112.

Love J.F. 1995. McDonald's: Behind the arches. (Rev. Ed.) Batnam Books, New York.

McDonald C.J. 1998. The evolution of Intel's Copy EXACTLY! technology transfer method. Intel Tech. J. (Quarter 4) 1-6.

March J.G. 1991. Exploration and Exploitation in Organizational Learning. Organ. Sci. 2(1) 71-87.

March J.G. 1996. Continuity and change in theories of organizational learning. Admin. Sci. Quart. 41 278-287.

March J., H. Simon 1958. Organizations. Wiley, New York.

Markus M.L., M.S. Silver 2008. A Foundation for the Study of IT Effects: A New Look at DeSanctis and Poole's Concepts of Structural Features and Spirit. J. Assoc. Inf. Sys. 9 609-632.

Meyer M.W. 2002. Rethinking Performance Measurement. Cambridge University Press, Cambridge, UK.

Miles M.B., A.M. Huberman. 1994. Qualitative data analysis: an expanded sourcebook. Sage Publications, Thousand Oaks (CA).

Nag R,. K.G. Corley, D.A. Gioia. 2007. The intersection of organizational identity, knowledge, and practice: Attempting strategic change via knowledge grafting. Acad. Management J. 50 821-847.

Nelson R. R., S. G. Winter. 1982. An Evolutionary Theory of Economic Change. Harvard University Press, Cambridge, MA.

Okhuysen G.A., B.A. Bechky. 2009. Coordination in Organizations: An Integrative Perspective Acad. Management Annals 3: 463 - 502.

Orlikowski W.J. 2002. Knowing in Practice: Enacting a Collective Capability in Distributed Organizing. Organ. Sci. 13(3) 249-273.

Orlikowski W.J., S.V. Scott. 2008. Sociomateriality: Challenging the Separation of Technology, Work and Organization. Acad. Management Annals 2(1): 433-474.

Pentland B.T., M.S. Feldman. 2005. Organizational routines as a unit of analysis. Ind. Corp. Change 14(5) 793-815.

Pentland B.T., M.S. Feldman. 2008. Designing routines: On the folly of designing artifacts, while hoping for patterns of action. Inform. Organ. 18(4) 235-250.

Pentland B.T., M.S. Feldman, M.C. Becker, P. Liu. 2012. Dynamics of organizational routines: a generative model. J. of Management Studies 49(8) 1484-1508.

Rerup C., M.S. Feldman. 2011. Routines as a source of change in organizational schema: The role of trial-and-error learning. Acad. Management J. 54(3) 577-610.

Pentland B.T., H.H. Rueter. 1994. Organizational routines as grammars of action. Admin. Sci. Quart. 39(3) 484-510.

Raisch S., J.B. Birkinshaw, G. Probst, M.L. Tushman. 2009. Organizational ambidexterity: Balancing exploitation and exploration for sustained performance. Organ. Sci. 20 (4) 685-695.

Rivkin J. W. 2001. Reproducing knowledge: Replication without imitation at moderate complexity. Organ. Sci. 12(3) 274-293.

Simon H.A. 1947. Administrative behavior. Macmillan, New York. 
Simon H.A. 1955. A behavioral model of rational choice. Quarterly J. of Economics 69 99-118.

Suchman L. 1987. Plans and situated action: The problem of human-machine interaction. Cambridge University Press, Cambridge, UK.

Suchman L. 2007. Human-Machine Reconfigurations: Plans and Situated Actions, 2nd ed. Cambridge University Press, Cambridge, UK.

Suddaby R. 2006. What grounded theory is not. Acad. Management J. 49 633-642.

Szulanski G., R.J. Jensen. 2004. Overcoming Stickiness: An Empirical Investigation of the Role of the Template in the Replication of Organizational Routines. Managerial \& Decision Economics 25 347-363.

Szulanski G., R.J. Jensen. 2006. Presumptive adaptation and the effectiveness of knowledge transfer. Strategic Management J. 27(10) 937-957.

Szulanski G., R.J. Jensen. 2008. Growing through copying: The negative consequences of innovation on franchise network growth. Res. Policy 37(10) 1732-1741.

Teece D., G. Pisano, A. Shuen. 1997. Dynamic capabilities and strategic management. Strategic Management J. 18 509-533.

Tsoukas H., R. Chia. 2002. On Organizational Becoming: Rethinking Organizational Change. Organ. Sci. 13(5) 567-582.

Turner S.F., V. Rindova. 2012. A balancing act: How organizations pursue consistency in routine functioning in the face of ongoing change. Organ. Sci. 23(1):24-46.

Van de Ven A.H., M.S. Poole. 1995. Explaining development and change in organizations. Acad. Manage. Rev. 20 (3) 510-40.

Van Maanen J. 1979. The fact of fiction in organizational ethnography. Admin. Sci. Quart. 24 539550.

Winter S.G. 1995. Four Rs of profitability: rents, resources, routines, and replication. C. Montgomery, ed. Resource-based and Evolutionary Theories of the Firm - Towards a Synthesis. Kluwer, Dordrecht, 147-178.

Winter S.G. 2010. The Replication Perspective on Productive Knowledge. H. Itami, K. Kusunoki, T. Numagami and A Takeishi, eds. Dynamics of Knowledge, Corporate Systems and Innovation. Springer-Verlag, Berlin, 93-119.

Winter S.G., G. Szulanski. 2001. Replication as Strategy. Organ. Sci. 12(6) 730-743.

Winter S.G., G. Szulanski, D. Ringov, R.J. Jensen. 2012. Reproducing Knowledge: Inaccurate Replication and Failure in Franchise Organizations. Organ. Sci. 23 672-685

Zbaracki M.J., M. Bergen 2010. When truces collapse: A longitudinal study of price adjustment routines. Organ. Sci. 21 955-972. 


\section{Figure 1 - Data Structure}

\section{Empirical observations}

Copy exactly/replication supports product quality and reliability
Copy exactly/replication allows using origin template as referent

"if we are aligned we can see where we are drifting"

Copy exactly/replication allows coordinating views and actions

Copy exactly/replication allows monitoring changes and their impact

Change/innovation allows introducing new ideas to develop process, technology

Change/innovation supports alignment to global standards (i.e. ISO, Six Sigma)

Change/innovation supports continuous improvement

Change/innovation allows drawing on local knowledge and expertise

Big Rules, Exceptions List, Model support alignment to template (transfer)

through aligning view and actions across sites (i.e. how and how far to align)

Audits support long-term alignment (post-transfer) through detecting gaps in

alignment/instances of loss of alignment across sites

FINAO team supports alignment (transfer) through aligning views and actions across sites (i.e. how and how far to align) and enforcing alignment by condemning deviations

US and UK management support copy exactly (transfer)

US Management supports audits (post-transfer)

Creation of ECR (post-transfer), supports the introduction of changes

(leapfrogging) and allows local autonomy

Revised Model (post-transfer), supports introduction of changes including

alignment to standards and product/process/tool improvement

Gaps in Model definition provide opportunities for adaptation (transfer)

Local Engineering communities (transfer) work under the radar to introduce

minor changes

Engineering Forum community (post-transfer) supports innovation and

continuous improvement

Local (UK) Management team (post-transfer) supports continuous improvement

and promotes alignment to global company standards

\section{Theoretical observations}

Theoretical constructs

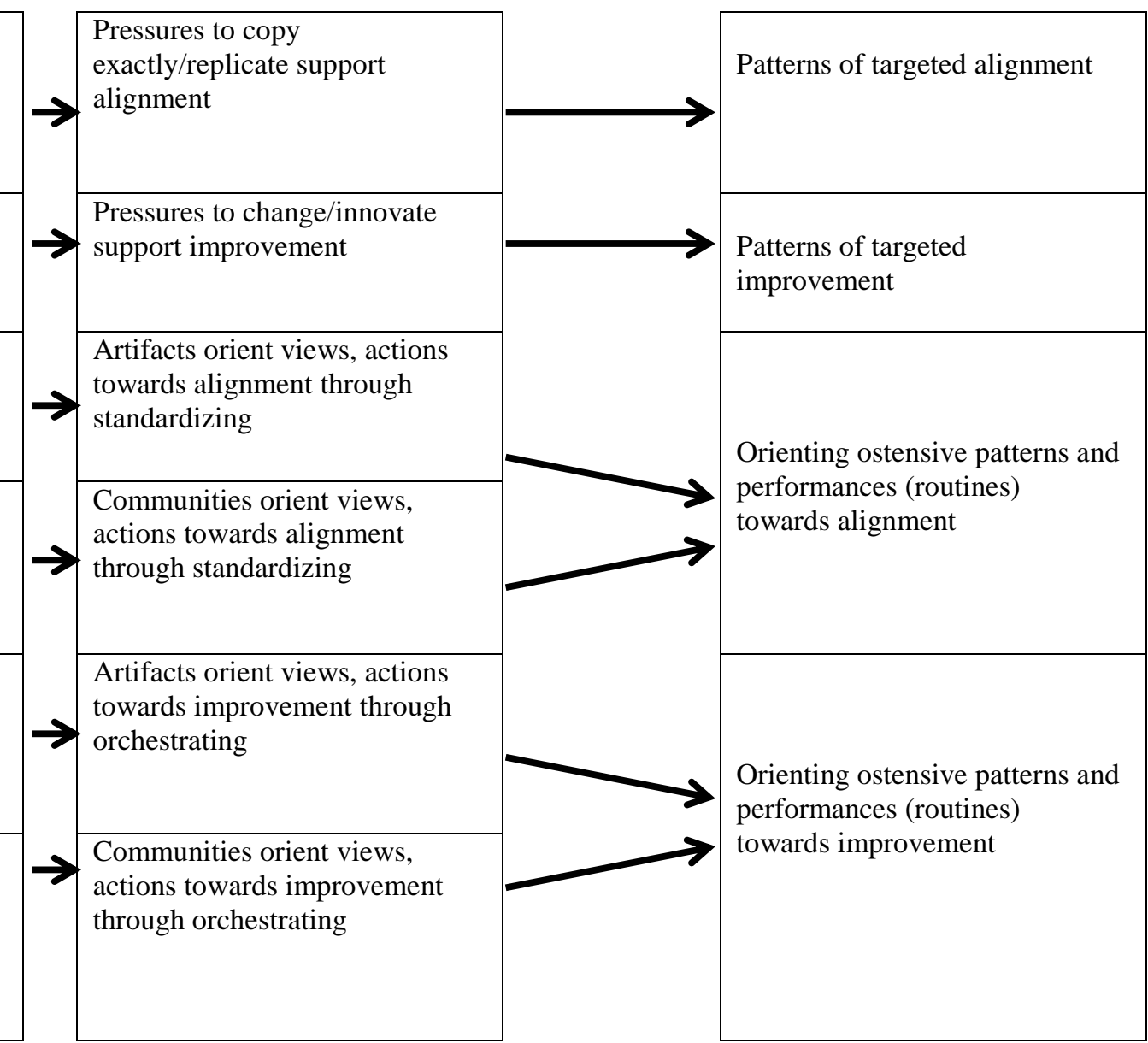


Figure 2 - Theoretical Framework: a Model of How Organizations Enact Contrasting Goals and Pressures

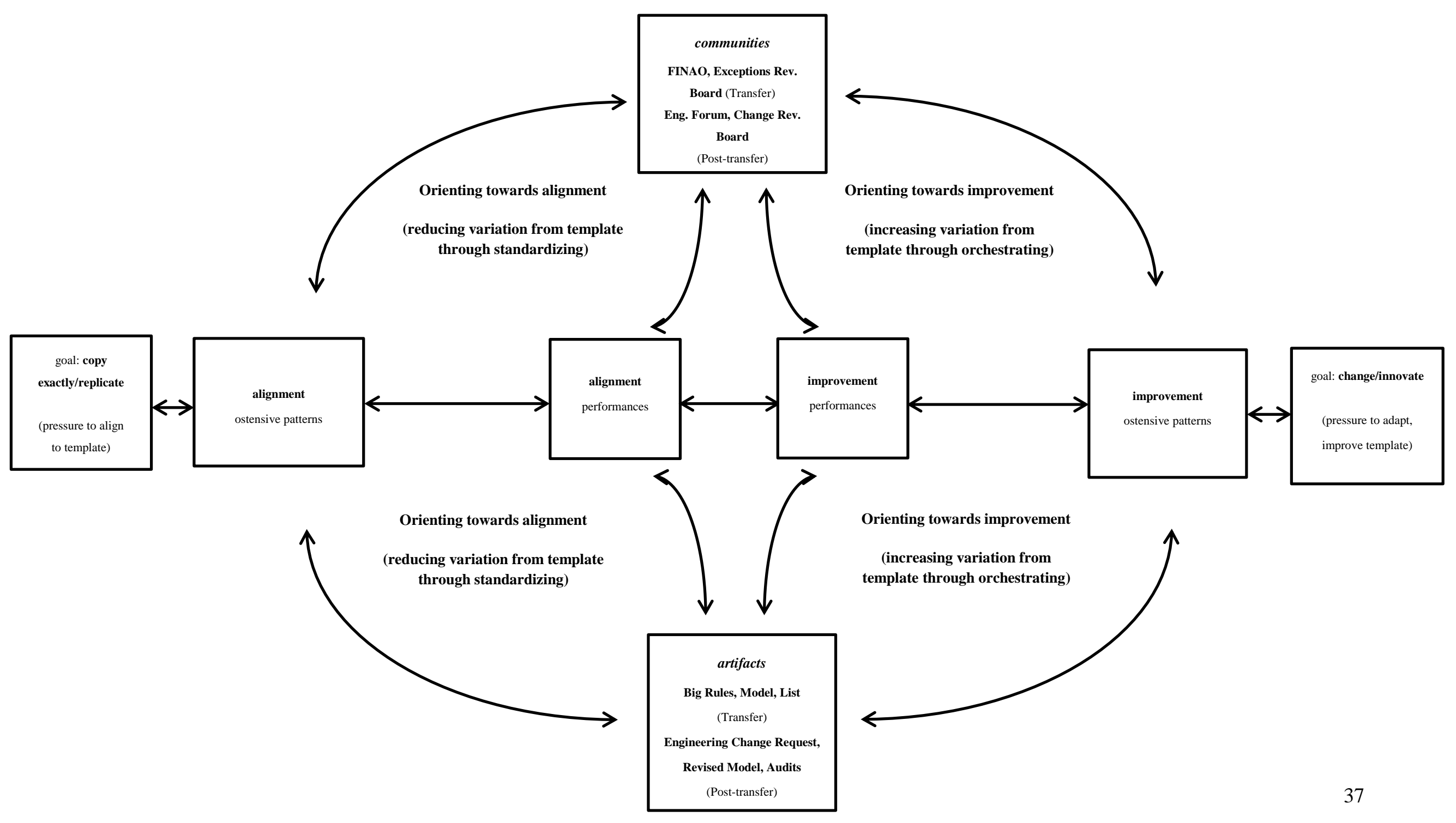


Table 1 - Interviews Protocol: Examples

\author{
Interviews with Project Manager (destination site organization) \\ Name, position, role, department, division, site organization
}

\title{
Transfer
}

What are the drivers behind the transfer?

Why "copy exactly"? How do you plan to implement it?

What is the project structure? What is the timing for each phase?

What will need to be done with respect to product, processes, tools and facilities to realize the transfer?

What are the success criteria for the project, for each phase?

How far should it be alignment? How important is it to be aligned? How feasible?

What are the criteria to establish whether and how far the sites are aligned?

Which are the processes to identify and deal with differences and exceptions?

What are the main characteristics of each site? What are the differences and similarities across the sites?

What are the potential failures/obstacles you foresee (people, processes, product, tools, infrastructures)?

What are the potential benefits (financial, learning etc)?

Which (management + technical) tools, methods and resources are being put in place to facilitate the transfer?

\section{Post-transfer}

How far are you aligned?

What are the weak areas or obstacles? What is being done to remedy this?

What in your view has succeeded; what has failed?

Which tools, methods and resources are being put into place for this stage?

Have relationships/structures/cultures/motivations changed (across sites, within sites, between site and global company)? If yes, how have they changed?

In the future should it be alignment or drift?

How important is it to stay aligned? How feasible?

Interviews with Lead Engineer (origin site organization)

Name, position, role, department, division, site organization

\section{Transfer}

How would you describe your organization/your product?

Can you describe how the decision to copy exactly was communicated/received?

What do you think about [destination]/copying / [origin]/ adopting your product/process?

How important is alignment?

How would you describe the status of your product? process? procedures? tools? facilities?

How do you identify/capture the processes to be transferred?

What kind of obstacles to transfer do you foresee? What kind of opportunities?

\section{Post-transfer}

What progress have you made towards identifying differences in practices and procedures across [origin] and [destination] since revealing the yields?

Are there still differences? Where are the differences located (i.e. which processes and process levels)?

Can we go through some examples of lower-level procedures that appear not to be aligned. Can you describe these procedures to me in detail?

Can you explain how they are interpreted/executed at [origin] vs. [destination]?

What are the differences due to? How/when were the differences detected?

How far would you say that you are aligned at this point in time? 
TABLE 2

Patterns of Alignment and Improvement

\section{First Order Concepts and Representative Quotations}

\begin{tabular}{|c|c|}
\hline $\begin{array}{l}\text { Second Order } \\
\text { Themes }\end{array}$ & $\begin{array}{l}\text { Overarching } \\
\text { Dimensions }\end{array}$ \\
\hline $\begin{array}{l}\text { Pressures for copy } \\
\text { exactly/exact } \\
\text { replication support } \\
\text { alignment }\end{array}$ & $\begin{array}{l}\text { Patterns of } \\
\text { targeted } \\
\text { alignment }\end{array}$ \\
\hline
\end{tabular}

When the push comes to the shove and you have a problem somewhere and you find you can't really say why one thing is different from another because there are so many differences. My experience is that the cost is higher in those cases than the costs of being aligned.

So we are going to release the variables one at a time and keep everything else exactly the same, exactly the same product, exactly the same process, everything the same.

\section{Alignment supports keeping track of (current and future) changes}

Lack of codification and alignment ([at process] level 2, 3, etc.) breeds the inability to detect change and implies a lack of control. [We need] a controllable process [...] otherwise differences come out

[In a previous transfer, where things had been allowed to drift apart] they went to audit some systems and they found that those systems instead of taking 200 hours to test they were shipping them after two days or something like that. How could you do that? [We thought] what are you guys at, this is crazy.

With [a previous transition] we had many, many alignment conversations. But [...] we were allowed to diverge. And, later, we said: why on earth did we do that? Why didn't we just keep the same? So this time we went out and did that. 


\section{Product maturity}

[Origin] was very immature in its development of process and documentation. It's a Rolls Royce, right? You handcraft it.

I think we realized that that's immature, you've got to get more discipline in the way you build your product, in the way you test it, in the way you capture your results.

Initially it was copy exactly, but, with this kind of product, now we need to improve.

\section{Global standards}

Doing things by heroics (individual level), [...] a procedure to do it (project level)..., a procedure for doing any framework on any products (process level); [...] a welldefined process (methodology).

\section{ISO and Six Sigma don't stifle creativity}

[Global corporation] has to work as one company. One process/one standard. You do not have different ways of doing things, just one way [...] They think we [UK] should copy everything. But there is a need to globalize.

\section{Innovation, improvement, and learning}

There may also have been an engineering view that copying prevented improvement. [...] Does it stifle creativity if you force two engineering groups in different parts of the world to copy one another? And you've got obstacles to change anything?

If basically we try to force [destination] to be our junior partner, if we basically communicate to them that they have nothing to add, that basically their job is to take what we give them and just build it - in this case you have a mindless set of slaves that they're not only going to sabotage it, but also you are not encouraging any innovations and not making use of those people.

It was really to ensure that we built a mirror image and help [destination] to understand why that has to be, but then also build something that makes people understand that we value their innovation and that we want their continuous improvement. [...] we have to develop a structure that allows people to innovate

Once people started this they realized how fun it can be to transition a product, to be teachers as well as experts. And that it is not always easy, your vision of what is gonna end up being the result is not always the same as reality that people have a way of driving in a direction that you never foresaw. And that's OK.

The question is whether that's OK or not, to be globally misaligned or not. I personally think that being misaligned is not a bad thing.

\section{Adaptation}

Now that we know that we have been successful, we can release another variable that is the supply chain variable, and we start to develop that, to localise the supply chain. It is just a matter of controlling the amount of variables.

Pressures for change/innovation support improvement
Patterns of targeted improvement 
TABLE 3

Role of Artifacts in Orienting Towards Alignment or Improvement

First Order Concepts, Observations and
Representative Quotations

Artifacts reduce variation through standardizing

\section{Big Rules}

"We have a 'Big Rule' thing, that we are going to have an identical process"

"The 'Big Rules' tool, where everything has to be the same, that's been a key tenet"

"The Big Rules have been a tremendous guiding force [...] it allowed an establishment of guidelines that made it easier to flow down to individual contributors"

"150 different processes have been identified. The aim is to 'Mirror Image' the processes in place currently at [US site]".

"We are going to make use of all US manufacturing procedures, tools, fixtures and carts unless they are in conflict with local laws"

"We are introducing US best practices at both locations to keep the process identical"

"The supply base to UK site will be the same as supply base to US site (any exceptions are documented)"

Example of alignment performances enacted through Big Rules (Drag \& Drop):

US and UK counterparts working on standardizing the reporting process across sites. "The whole point is that we have to get to a conclusion together and become aligned because part of the whole 'drag and drop' process is that the metric part has to be exactly the same. There are things that we could have done better. We need to start to work on those globally"

Engineers changing an assembly sequence to 'mirror' the US labour structure

\section{Model}

"There is only one process [...], and it is global, there is only one database and people see the same thing in all parts of the world and for all products. All the way to the field"

"Manufacturing needs to support each fragment of the [US]process"

"Documents will be made available on a web page. They lay out globally agreed process levels"

"The information will go through the [global, computer-embedded] manufacturing process and it's pretty well controlled, documented"

"We do have a [common codified version of] process and it defines what the steps of the process are"

"Lots of work in closing the naming differences with NC codes. Failures can be logged on with different codes"

Example of alignment performances enacted through Model:

Using the Model as referent in resolving failure codes: "If something fails the test, we have first level Failure Analysis and we go straight to this knowledge base and make use of that [...] There is a step-by-step description of how to recover from individual failure codes. Only in this way we can know for sure that we are doing the same thing"

Test technicians delete the scanning portion of the test process (not included in the

Role of artifacts in orienting ostensive patterns and performances towards alignment
Artifacts orienting routines towards alignment or improvement 
Model) to support alignment: "Americans don't do it"

\section{Exceptions List}

"We have actually devised a process to revise the rules and to check what are the exceptions"

"What we have is an exception process whereby people have to detail exactly what the difference is, why it is there, the consequences it brings, and then it goes up to people where they say I approve this difference or I don't. Allowing a minimal amount of change to creep in. Basically what we bring in are very well controlled and understood differences"

"UK will duplicate all US processes. Exceptions will be documented"

Example of alignment performance enacted through the Exceptions List:

Discussion around whether a particular exception in process definition between the sites should be further discussed or agreed and closed: "Closure is when $99 \%$ is there. But this [item] is still not closed"

\section{Audits}

"How are we going to make sure that we are still aligned? That things haven't slipped through the cracks? Audits check on process alignment and report differences"

"By the time we capture it [a difference] in an audit, it has already diverged. But if we keep control, we will have a deviation that is this big, rather than this big"

"If we are not clear right now about how we are going to do these changes I suspect that we are starting to diverge between the sites. So now we are talking about this auditing trying to see if any of these alignment issues are significant before we call them a higher level exception".

"The danger is going to be if one site makes continuous improvement and doesn't communicate it to the other site and then, until we see it in an audit, we lose the benefit of that at the other site"

Example of alignment performance enacted through audits:

Audits are introduced by US management in Stage 2 in response to the fear of losing control over drift and in order to rein the process back in towards alignment. During the course of an audit they found changes that had not been communicated to the other site: "Why didn't you tell us? That would have been a great thing to know six months ago when you did it, and as a result we lost a little bit, [...] wouldn't it have been great if we could have done that earlier, on both sites?"

\section{Artifacts increase variation through orchestrating}

\section{Revised Model}

"Now we are going to release the process and introduce the changes"

"Currently processes are changing rapidly [...]The shop floor has moved on from one revision [of the Model] to the next with the aim to achieve a global level"

"So if we decide for whatever reason, an improvement, or quality, if we decide to change something on the specification of that part all the way, the information will go through [our] manufacturing process and it's pretty well controlled, documented"

Role of artifacts in orienting ostensive patterns and performances towards alignment
Artifacts orienting routines towards alignment or improvement
Role of artifacts in orienting ostensive patterns and performances towards improvement 
[company]global initiatives and processes, to align itself to the [company's] global standards"

"We always said that we would have the same infrastructure, but to have $50 \%$ of people's time trying to adapt [UK site to US site] we can't support that because we have 148 lines of exceptions. Maybe we need to revise that" (UK Director)

\section{Example of improvement performance enacted through the Revised Model:}

Model revised to upgrade US training procedures to more advanced dedicated UK training system: "If you have the budding system [as in the US] you don't have the same consistency [across training experiences]. They don't have the value added at the skill level that we have out here which drives consistency"

\section{Engineering Change Request (ECR) Process}

“Opportunities for improvement can drive an ECR"

"We have to develop a structure that allows people to innovate, and then through the change management process say, here's a great idea, why don't we implement this at both sites"

"Basically my vision is that [the ECR] would be relatively easy to implement given that we've got the foundation processes, and that as long as people are communicating site to site, we both know the product, and we both know that it is crying out for continuous improvement".

"[we are going] To introduce a change control process. According to this process, every change that is raised has to be reviewed by a panel of experts and/or managers. Documents will be made available on a web page. They lay out globally agreed process levels [...] That helps introducing changes"

\section{Example of improvement performance enacted through the ECR:}

UK manager explaining the consequences of not making a particular change an Engineering Change Request: "I think the principle is right that it is cross-functional. $[\ldots][$ If] an engineer $[\ldots]$ tries to make that change, $[\ldots]$ they can make the change completely in their own little box and they don't let anybody see how to do it. So they change it and nobody else knows. And then they find out that somebody should have known and they get a call in the middle of the night saying "why is this screw gold when it should be silver", or "Did you know I know that" kind of conversation. [...] They get to a point where they are trying to drive a change, $[\ldots]$ and they start getting frustrated that they can't change something.
Role of artifacts in orienting ostensive patterns and performances towards improvement
Artifacts orienting routines towards alignment or improvement 


\section{TABLE 4}

\section{Role of Communities in Orienting Towards Alignment or Improvement}

\section{First Order Concepts, Observations and Representative Quotations}

\section{Communities reduce variation through standardizing}

\section{FINAO}

"[Alignment] was really driven from the FINAO team on both sites"

"All exceptions are revised by the Global Management Team. The team is called FINAO (Failure is Not An Option)"

"Exceptions Level 1 \& 2 have to be solved at the FINAO level"

“Green stands for 'complete'. Yellow, 'not complete, but plan in place', red means 'not complete, at risk for required date,",

\section{Alignment performances enacted through FINAO:}

FINAO discussion about whether a specific process sequence is to be declared fully or partially aligned. UK and US Managers discussing whether they are or are not yet aligned: "We have agreed that Green is "path completed" so this is "a plan has been made but not executed", so it is a Yellow" (US Manager) [...] It depends on how you phrase it. The Big Rule may be Green but not the Action (UK Manager)"

While performing the 'de-kitting routine' technicians are discussing how to revise the step sequence to reflect a decision taken during a recent FINAO meeting: "To give you an example [...]: the CPU board that is used for [this product], one operator here bolts the whole CPU; in the US they [...] split that job among six people. So one person does one part of it, the next another part, it is more like an assembly line. [...] The span of the job is maybe twenty minutes, [so we have to] split it into two- or three-minutes operations where [we] can learn exactly what we are supposed to do, and do a quality job for that particular item, and then it moves on to the next person"

\section{Exceptions Review Board}

"Everybody has witnessed how bad it can be with [a previous transfer project], and they know that what you have got right now is a low cost model if you can keep it that way. So the costs of drifting are really great"

"I don't really see the Exceptions Process go away. We need to bring Exceptions back on the table"

\section{Example of alignment performance enacted through the Exceptions Review Board:}

Discussion taking place during one of the Review Board meetings: "[There are] people in the hallways saying 'I heard, I heard'. I say pick up the phone and do something. If we pick up something we need to nip it in the bud before it becomes a problem"

\section{Communities increase variation through orchestrating}

\section{Engineering Change Review Board}

"ECR is going to help that, because of the structure that has been put in place and the tool, but also the meetings are actually even more important than the tool itself; we have a good cross-functional representation there, and greater visibility of what 
engineering is thinking about changing which is also helping them to understand the cross-functional impact of that. At the end of the day it is normally an engineering decision about what to change but people in my position can help smooth out change by highlighting potential problems.

"We cannot afford that a site resolves a problem and then throws it over the wall to the other site"

\section{Example of improvement performance enacted through Change Review Board:}

"That's the kind of discussion that the Change Review process has. When the original request comes in, does the requester understand all the impacts, and that's why the change review boards are supposed to be cross-functional. Because if they are not, than an engineer thinks "well, this doesn't impact on materials" they don't care, and that's the wrong answer. And if you go too far down the road before you get materials input into that then you have a problem. So the change review board is supposed to prevent that from happening"

\section{Engineering Forum}

"We make changes as part of our job. Our work is to make improvements. That's what the Forum is about"

"A cross functional team is supposed to share that information [about a proposed change] and start this [conversation], because of this we have to do $x$, what would that mean do you think. That for me would be an informal start to a change request. They start the discussion in that Forum and continue outside in the corridors, whatever"

"There are informal mechanisms to [encourage] changes to be brought up, discussed, talk to people, this is just an idea we haven't decided it'll happen yet, and only at that point should it become a [formal] request. Our view is, maybe you don't get the support of all the cross-functional operations but you get awareness, everybody to know what is going on outside their own area" [...]

"If you capture the problems at an informal stage, then the formal stage will have a chance" [...] "Informal, undocumented observations must be brought to the fore and followed up on. We need to build an informal network that will tie in and glue the more formal mechanisms"

Example of improvement performance enacted through the Engineering Forum:

At one of the Forum meetings a discussion takes place as to what changes need to be introduced to the manufacturing process to reflect improvements such as multiproduct, multi-platform standardization and ISO and standards alignment: "There are trade-offs between UK processes that are product-specific and US processes that are multi-product. There are also trade-offs between ISO approved and non-approved processes. Improvements cannot be delayed further"
Role of

communities in re-

orienting ostensive patterns and performances towards improvement
Communities orienting routines towards alignment or improvement 